\author{
AUS DEM LEHRSTUHL \\ FÜR NEUROLOGIE \\ PROF. DR. ULRICH BOGDAHN \\ DER MEDIZINISCHEN FAKULTÄT \\ DER UNIVERSITÄT REGENSBURG
}

\begin{abstract}
CHANGES IN
ADULT OLFACTORY BULB NEUROGENESIS

IN MICE EXPRESSING

THE A30P MUTANT FORM OF ALPHA-SYNUCLEIN
\end{abstract}

Inaugural-Dissertation

zur Erlangung des Doktorgrades

der Medizin

\begin{abstract}
der
Medizinischen Fakultät

der Universität Regensburg
\end{abstract}

vorgelegt von

Franz Marxreiter 



\author{
AUS DEM LEHRSTUHL \\ FÜR NEUROLOGIE \\ PROF. DR. ULRICH BOGDAHN \\ DER MEDIZINISCHEN FAKULTÄT \\ DER UNIVERSITÄT REGENSBURG
}

\begin{abstract}
CHANGES IN
ADULT OLFACTORY BULB NEUROGENESIS

IN MICE EXPRESSING

THE A3OP MUTANT FORM OF ALPHA-SYNUCLEIN
\end{abstract}

\author{
Inaugural-Dissertation \\ zur Erlangung des Doktorgrades \\ der Medizin \\ der \\ Medizinischen Fakultät \\ der Universität Regensburg
}

vorgelegt von

Franz Marxreiter

2010 
Dekan:

1. Berichterstatter:

2. Berichterstatter:
Prof. Dr. Bernhard Weber

PD Dr. Beate Winner

Prof. Dr. Andreas Luchner

Tag der mündlichen Prüfung: 14.10.2010 
Für meine Eltern 


\section{Inhaltsverzeichnis}

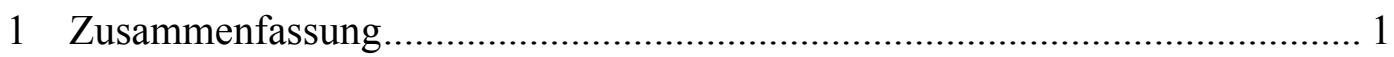

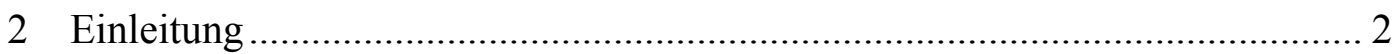

3 Mechanismen der alpha-Synuclein induzierten Neurodegeneration ................ 7

3.1 alpha-Synuclein (Park1 und Park4) …................................................... 7

3.2 Pathologie und Pathobiologie des IPS ................................................ 8

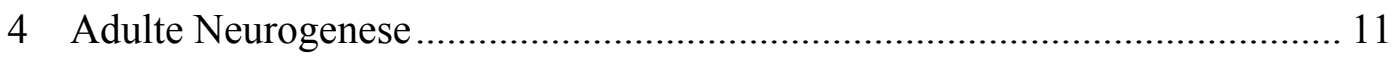

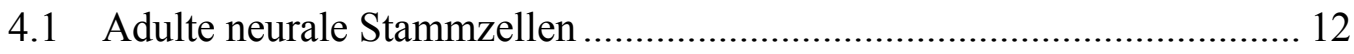

4.2 Adulte Neurogenese im Bulbus Olfaktorius ......................................... 12

5 Zusammenfassung der Publikation „Changes in adult olfactory bulb neurogenesis in mice expressing the A30P mutant form of alpha-Synuclein" (European Journal of Neuroscience, Vol. 29, pp. 879-890, 2009)................. 14

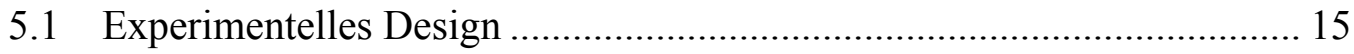

5.2 Die Expression von A30P alpha-Synuclein ist regulierbar..................... 15

5.3 Die Expression von A30P alpha-Synuclein im Bulbus Olfaktorius reduziert die adulte Neurogenese im System SVZ/OB.......................... 16

5.4 Suppression der alpha-Synuclein Expression beeinflusst die adulte Neurogenese im Bulbus Olfaktorius ................................................... 16

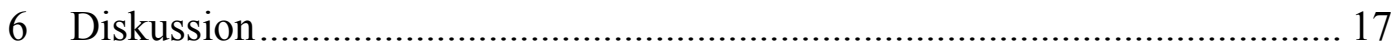

6.1 Die A30P alpha-synuclein Maus als Modellsystem früher alpha-Synuclein assoziierter Pathologie ....................................................................... 17

6.2 Einfluss von A30P alpha-Synuclein auf die zelluläre Plastizität............. 18

6.3 Modulation der alpha-Synuclein Expression und zellersatzbasierte Therapieformen des IPS 
7 Literaturverzeichnis

8 Manuskript: Changes in adult olfactory bulb neurogenesis in mice expressing the A30P mutant form of alpha-Synuclein 34

9 Anhang 47

9.1 Verzeichnis der verwendeten Abkürzungen ........................................ 47

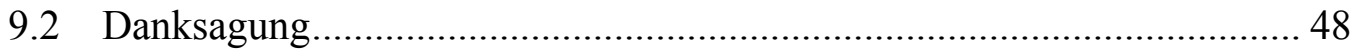

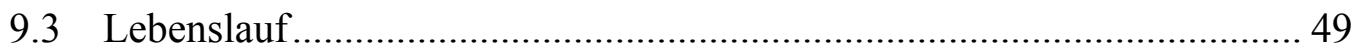




\section{Zusammenfassung}

In familiären und idiopathischen Formen des Morbus Parkinson wird früh im Verlauf der Erkrankung pathologische alpha-Synuclein Akkumulation im Bulbus Olfaktorius gefunden. Während die Akkumulation der Wildtypform des präsynaptischen Proteins alpha-Synuclein ein Kennzeichen des idiopathischem Parkinsonsyndroms ist, zeigen Patienten mit einer A30P Punktmutation im alpha-Synuclein Gen einen frühen Krankheitsbeginn sowie einen fulminanten klinischen Verlauf. Im Bulbus Olfaktorius integrieren täglich physiologisch neu gebildete Nervenzellen durch adulte Neurogenese.

Diese Arbeit untersucht die Veränderung der adulten Neurogenese in der subventrikulären Zone und dem Bulbus Olfaktorius in einem, durch Doxycyclin regulierbaren (tet-off) Mausmodell für Synucleinopathien. Humanes A30P alpha-Synuclein wird unter der Kontrolle des Kalzium/Calmodulin- abhängigen Protein Kinase II alpha (CaMK)Promoters überexprimiert.

In A30P alpha-Synuclein exprimierenden Tieren fand sich alpha-Synuclein im Bulbus Olfaktorius insbesondere in der Glomerulärzellschicht. Die Analyse der adulten Neurogenese zeigte keine Unterschiede bzgl. der Proliferation in der SVZ jedoch eine reduzierte Zahl neuer Neurone in der Granulärzellschicht sowie weniger dopaminerge Neurone in der Glomerulärzellschicht. In diesen Regionen findet sich vermehrt Programmierter Zelltod. Durch Unterdrückung der alpha-Synuclein Expression mit Doxycyclin konnte diese Reduktion der adulten Neurogenese verhindert werden.

Diese Resultate zeigen unter Expression von A30P alpha-Synuclein eine reduzierte adulte Neurogenese im Bulbus Olfaktorius. Eine Unterdrückung der alpha-Synuclein Expression fördert das Überleben der integrierenden neu gebildeten Zellen. Folglich könnnte die Modulation alpha-Synuclein assoziierter Pathologie neu gebildete Nervenzellen retten und dadurch eine zur adulten Neurogenese komplementäre therapeutische Strategie darstellen. 


\section{Einleitung}

Das idiopathische Parkinsonsyndrom (IPS) ist die zweithäufigste, altersassoziierte neurodegenerative Erkrankung und betrifft aktuell bis zu $2 \%$ der über 60 -jährigen. Für die folgenden Jahrzehnte wird durch die zunehmende Alterung der Bevölkerung in den westlichen Ländern von einer steigenden Inzidenz ausgegangen (Olanow et al 2009). Klinisch imponieren beim IPS die Kardinalsymptome Rigor, Tremor, Hypokinese und posturale Instabilität. Zusätzlich treten im zeitlichen Verlauf der Erkrankung eine Vielzahl von nicht-motorischen Symptomen wie z.B. die Riechstörungen auf. Die im Krankheitsverlauf häufig vor den motorischen Symptomen des IPS auftretende Riechstörung in Form der Hyposmie oder Anosmie (Ponsen et al., 2004) gilt als ein Surrogatmarker des IPS (Siderowf et al., 2005).

Ein gestörter Ablauf von Proteinfaltung, -polymerisierung und -aggregation gilt als wesentlichen Schritt in der Pathogenese einer Reihe von neurodegenerativen Erkrankungen (Rubinsztein, 2006). Im Falle des IPS konnte das Protein alpha-Synuclein als aggregierendes Agens identifiziert werden (Polymeropoulos et al., 1996). Das physiologisch als Monomer vorliegende alpha-Synuclein lagert sich über oligomere und fibrilläre Zwischenstufen als Lewy Körper in den Nervenzellen ein. Die Substantia Nigra pars compacta gilt beim IPS als besonders vulnerabel für neurodegenerative Prozesse. Sie beeinflusst mit ihren dopaminergen Projektionsneuronen zum Striatum die Feinabstimmung von Bewegungen. Im Verlauf der Erkrankung werden jedoch auch andere Regionen des Gehirns von den degenerativen Prozessen erfasst. Beispielsweise zeigen das olfaktorische System und der Hirnstamm frühe pathologische Veränderungen (Braak et al., 2003).

Die Assoziation der Hyposmie mit, neuropathologisch früh auftretender, alpha-Synuclein Pathologie im Bulbus Olfaktorius (OB) führt möglicherweise $z u$ einer neuen pathogenetischen Betrachtung der 
Erkrankung (Braak et al., 2003; Olanow et al., 2009). In der Tat könnte der Symptomenkomplex aus Anosmie gemeinsam mit gastrointestinalen Störungen (wie z.B. Obstipation) und REM-Schlafstörungen eine frühe Form des IPS darstellen (Langston, 2006) in deren Verlauf sich dann sowohl die motorischen Kardinalsymptome als auch andere schwer behandelbare nicht-motorische Symptome zeigen (Olanow et al. 2009). Daneben zeigen sich pathologische Veränderungen auch im Mesokortex und im Neokortex (Del Tredici et al., 2002; Forno et al., 1996). Im Endstadium der Krankheit finden sich pathologische alpha-Synuclein Ablagerungen im gesamten Gehirn wobei neben dopaminergen Zentren auch eine Vielzahl nicht-dopaminerger Systeme betroffen sind (Braak et al., 2004).

Trotz Kenntnis der Früh- und Kardinalsymptome sowie der neuropathologischen Charakterisierung der Erkrankung über das dopaminerge System hinaus steht derzeit keine kausale Therapie des IPS zur Verfügung. Die medikamentöse Therapie des IPS basiert heute größtenteils auf der Substitution des Neurotransmitters Dopamin. Die Therapie mit Dopaminergika in Frühstadien des IPS hat sich im Hinblick auf die Behandlung der motorischen Störungen als sehr effektiv erwiesen wodurch IPS-Patienten bei frühzeitiger Therapie eine normale Lebenserwartung haben. Jedoch kann durch die symptomatische Therapie mit Dopaminergika der panneuronale Zellverlust und die damit einhergehende Progression der Erkrankung, welche eine Vielzahl an für den Patienten belastenden Symptomen mit sich bringt, nicht verhindert werden (Olanow et al., 2009).

Die Suche nach einer kurativen Therapie für das IPS hat somit große Bedeutung. Als ein kurativer Ansatz gilt der zelluläre Ersatz von Nervengewebe welcher den Verlust an Neuronen kompensieren könnte. Im Fall des IPS, welches mit einer normalen Lebenserwartung einhergeht, müssen die Ergebnisse dieser stammzellbasierten Transplantationsansätze mit den bereits existierenden medikamentösen Therapien 
konkurrieren können, mit einem akzeptablen Operationsrisiko einhergehen und ein niedriges Nebenwirkungsspektrum aufweisen (Lindvall et al., 2010).

Die ersten Transplantationen von fötalem Mittelhirngewebe in das Striatum von insgesamt acht Patienten vor 20 Jahren haben die prinzipielle Machbarkeit des Transplantationsansatzes bewiesen (Mendez et al., 2008). Jedoch waren die Ergebnisse bezüglich des klinischen Benefits sehr unterschiedlich (Braak et al., 2008). Darüber hinaus scheint das transplantierte Gewebe von der alpha-Synuclein Pathologie erfasst zu werden. In zwei von drei Studien fanden sich in den Autopsien der transplantierten Gewebe in einem geringen Teil (4\%) der Neurone Lewy Körper (Li et al., 2008; Kordower et al., 2008).

Aktuell eröffnet sich durch die Reprogrammierung von Fibroblasten der Haut in pluripotente Stammzellen und dann in Neurone (Takahashi et al., 2007; Hockemeyer et al., 2008) ein Weg zur Gewinnung von transplantierbarem autologem Gewebe. Es konnten bereits Fibroblasten von IPS-Patienten erfolgreich durch viralen Gentransfer reprogrammiert (Park et al., 2008) und dopaminerg differenziert werden. Ein funktioneller Benefit durch Transplantation von Neuronen welche aus induzierten Stammzellen differenziert wurden ist in einem Rattenmodell des IPS bereits beschrieben worden (Wernig et al., 2008). Aktuell ist jedoch unklar wie vulnerabel diese Zellen aufgrund ihres genetischen Profils auf lange Sicht sind und wie sie auf die im Transplantationsareal bestehende alphaSynuclein Pathologie reagieren (Lindvall et al., 2010; Kiskinis et al., 2010). Darüber hinaus müssen die bei diesem Ansatz noch bestehenden Probleme der malignen Entartung und der viralen Restaktivität dieser Zellen vor einem klinischen Einsatz gelöst werden (Soldner et al., 2009). Dennoch können induzierte Stammzellen aufgrund ihrer Verfügbarkeit, der vergleichsweise leichten Produzier- und Differenzierbarkeit und der Möglichkeit der Etablierung von Patientenzellbanken eine Vielzahl neuer Informationen liefern und unerlässliche Einblicke in die humane Pathogenese des IPS liefern (Lindvall et al., 2010). 
Eine weitere Möglichkeit der Verwendung von körpereigenem Gewebe ist die endogene Zelltherapie. Diese Form des Zellersatzes beruht darauf, dass im adulten Gehirn des Menschen die Neubildung von Nervenzellen aus neuralen Stammzellen physiologisch stattfindet (Eriksson et al., 1998; Sanai et al., 2004; Curtis et al., 2007). Diese, adulte Neurogenese genannte, Integration von neuen Zellen in ein funktionierendes neuronales Netzwerk stellt neben dem axonalen Wachstums und der synaptischen Reorganisation einen weiteren postnatalen neuronalen Adaptationsmechanismus dar. Dadurch eröffnen sich zusätzliche regenerative Fähigkeiten des Gehirns und ein potentieller weiterer Therapieansatz beim IPS. So lässt sich die adulte Neurogenese durch den Dopaminagonisten Pramipexol (Winner et al., 2009) sowie durch das Neurotrophin BDNF (Pencea et al., 2001) und den Wachstumsfaktor PDGF (Mohapel et al., 2005) steigern.

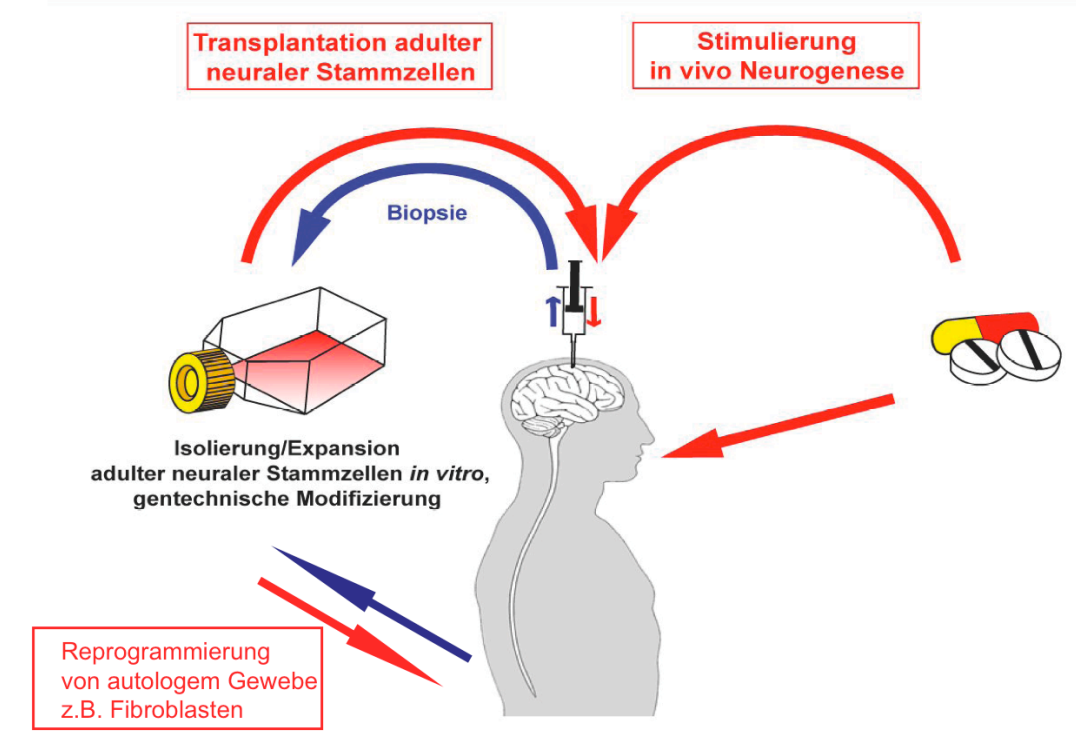

Abb. 1: Als Möglichkeiten zur endogenen Stammzelltherapie bieten sich Gewinnung, Expandierung und die anschliessende Retransplantation adulter neuraler Stammzellen sowie die medikamentöse Stimulierung der adulten Neurogenese in vivo an. (modifizierte Version von Klucken et al. 2002) 
Obwohl sich die hier vorgestellten Therapieansätze in ethischen (z.B. embryonale Stammzellen), logistischen (z.B. Verfügbarkeit von transplantierbarem Gewebe) und wissenschaftlichen (z.B. maligne Entartung) Fragen durchaus stark unterscheiden, stellt der Einfluss der alpha-Synuclein Pathologie auf das zum Zellersatz benutzte Gewebe und die postulierte, damit einhergehende Störung der Funktionalität des Zellersatzes bei allen Ansätzen ein gemeinsames Grundproblem dar (Lindvall et al., 2010; Brundin et al., 2008).

Zur Etablierung einer auf Stammzellen basierenden Therapie ist es also von zentraler Bedeutung die Migration sowie die Integration der neuen Zellen in das durch alpha-Synuclein pathologisch veränderte Gehirn zu untersuchen. Interessanterweise ist das System subventrikuläre Zone (SVZ)/OB eine der beiden Regionen des Zentralnervensystems (ZNS) in denen kontinuierlich neue Nervenzellen gebildet werden. Dort werden auch dopaminerge Nervenzellen laufend neu gebildet und in das neuronale Netzwerk des Bulbus Olfaktorius integriert. Dies eröffnet die Möglichkeit im olfaktorischen System Veränderungen der adulten dopaminergen und nicht-dopaminergen Neurogenese im alpha-Synuclein überexprimierenden Tiermodell zu untersuchen. Dadurch wird es möglich, ein Verständnis von den Mechanismen zu erhalten, welche die Etablierung von Zelltherapien beeinflussen. Es konnte bereits gezeigt werden, dass humanes wildtyp alpha-Synuclein die adulte Neurogenese im Bulbus Olfaktorius reduziert (Winner et al., 2004) und dass die A53T Mutation von alpha-Synuclein die Proliferation von adulten neuronalen Vorläuferzellen vermindert (Winner et al., 2008).

Die vorgelegte Arbeit untersucht die Expression der A30P Mutation von alpha-Synuclein in einem regulierbaren, transgenen Mausmodell. Dabei wird der Einfluss auf die adulte Neurogenese im Bulbus Olfaktorius mit Hilfe von Immunhistochemie untersucht. In diesem Tiermodell für Synucleinopathien kann die Dauer der Expression von mutiertem A30P alpha-Synuclein durch die Gabe des Antibiotikums Doxycyclin gesteuert 
werden (tet-off System). Somit kann nicht nur der Einfluss der A30P alphaSynuclein Mutation auf die adulte Neurogenese untersucht werden, sondern auch eine zeitliche Korrelation zwischen alpha-Synuclein Expression und adulter Neurogenese hergestellt werden.

Im Folgenden wird die zentrale Rolle des Proteins alpha-Synuclein sowie die Pathophysiologie des IPS dargestellt und die adulte Neurogenese im System SVZ/OB erläutert. Anschließend werden die Ergebnisse der Publikation "Changes in adult olfactory bulb neurogenesis in mice expressing the A30P mutant form of alpha-synuclein " erläutert.

\section{Mechanismen der alpha-Synuclein induzierten Neurodegeneration}

\section{1 alpha-Synuclein (Park1 und Park4)}

Das Protein alpha-Synuclein konnte erstmals 1996 durch die Untersuchung einer italienisch- (Polymeropoulos et al., 1996) und einer griechischstämmigen (Duvoisin et al., 1995) Familie mit dem Parkinsonsyndrom in Verbindung gebracht werden. Diese Familien trugen eine A53T Missensemutation im SNCA-Gen welches für alpha-Synuclein kodiert und auf Chromosom 4q21 liegt (Farrer et al., 2006). Die Krankheit wurde über mehrere Generationen autosomal-dominant vererbt (Polymeropoulos et al., 1996). Weitere Punktmutationen des alphaSynuclein Gens (A30P, E46K) sind durch familiäre Parkinsonsyndrome identifiziert worden (Kruger et al., 1998; Zarranz et al., 2004). Die für diese Arbeit relevante A30P Punktmutation wurde bei zwei Betroffenen einer deutschen Familie gefunden. Klinisch zeichneten sich diese Patienten durch ein früh auftretendes und schnell progredientes Parkinsonsyndrom aus (Krüger et al., 1998). Alpha-Synuclein ist ein Protein, bestehend aus 140 Aminosäuren, das keine kompakte Tertiärstruktur aufweist. Entdeckt wurde das Protein im elektrischen Organ des Aals "torpedo california“ (Maroteaux et al., 1988). Alpha-Synuclein liegt physiologisch als ungefaltetes, fadenförmiges Protein vor. In vitro Experimente zeigen, dass es in Abhängigkeit von seiner Umgebung polymerisieren kann, dadurch Protofibrillen sowie Fibrillen bildet und aggregiert (Conway et al., 2000). 
Die exakte physiologische Funktion von alpha-Synuclein ist bisher unbekannt und alpha-Synuclein Knockout-Mäuse zeigen phänotypisch keine Auffälligkeiten (Abeliovich et al., 2000). Exprimiert wird es insbesondere im embryonalen Gehirn wobei es sich vor allem in präsynaptischen Nervenendigungen findet und mit synaptischen Vesikeln assoziiert ist. Deshalb könnte die korrekte präsynaptische Funktion teilweise von alpha-Synuclein abhängen (Withers et al., 1997; Murphy et al., 2000). Aufgrund der Fähigkeit Membranen zu binden, könnte alphaSynuclein "lipid Rafts" fixieren und dadurch zur synaptischen Lokalisation von Vesikeln beitragen (van Rooijen et al., 2009). Auch eine Rolle in der Vesikelregeneration und der damit verbundenen Dopaminübertragung in präsynaptischen Endigungen wurde beschrieben (Abeliovich et al., 2000; Perez et al., 2002).

\subsection{Pathologie und Pathobiologie des IPS}

Pathologisches Korrelat der Parkinsonkrankheit sind amyloidähnliche, intrazelluläre Einschlusskörper, sogenannte Lewy Körper (Abb2A, Spillantini et al., 1997). Zusätzlich finden sich fadenförmige Strukturen,

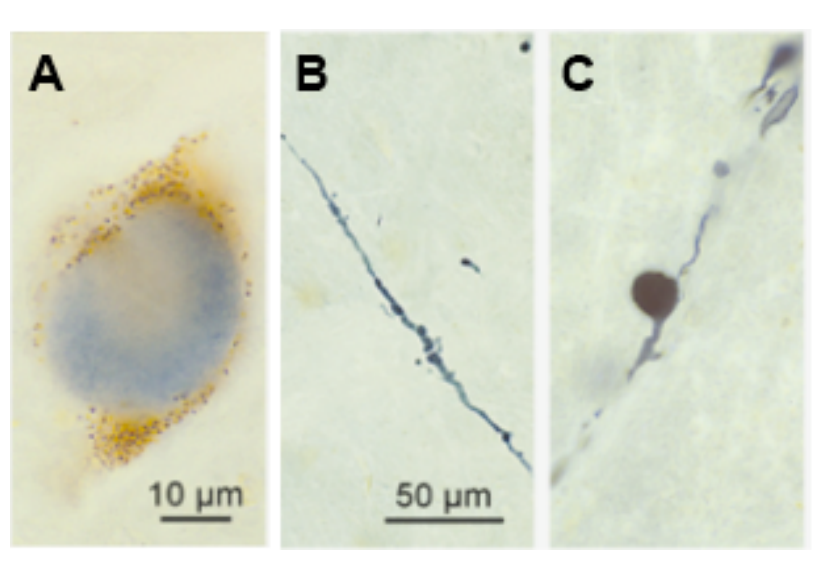
Gehirn eines IPS Patienten sind Lewy Körper (A) und Lewy Neuriten (B), welche kugelförmige Einlagerungen (C) aufweisen können (Braak et al., 2003).
Abb. 2: klassische Pathologische Veränderungen im sogenannte Lewy Neuriten (Abb. 2B). Die lichtmikroskopisch eosinophilen Lewy Körper enthalten Ubiquitin, welches eine wichtige Rolle beim proteasomalen Abbau von Proteinen spielt. Weitere Bestandteile sind Tubulin, Mikrotubulin assoziierte Proteine und das betaAmyloid Vorläuferprotein sowie abnormal stark phosphorylierte Neurofilamente. Alpha-Synuclein gilt jedoch als Hauptbestandteil dieser permanenten Ablagerungen (Sandmann-Keil et al., 1999). Lewy Neuriten 
sind alpha-Synuclein positive Nervenzellfortsätze und haben morphologisch die Gestalt von korkenzieherförmigen (Abb. 2B), mit Varikositäten und kugelförmigen Einlagerungen (Abb. 2C) versehenen Fäden haben (Braak et al., 2003).

Man nimmt heute an, dass sowohl Lewy Körper als auch Lewy Neuriten Endresultate des bereits oben beschriebenen Prozesses der Polymerisierung und Aggregation sind. Vermutlich bilden lösliche Synucleinmonomere zunächst oligomere Protofibrillen, aus denen daraufhin amyloidähnliche Fibrillen gebildet werden. Diese werden schließlich permanent im Neuron eingelagert (Conway et al., 2001; Conway et al., 2000; Abb. 3).

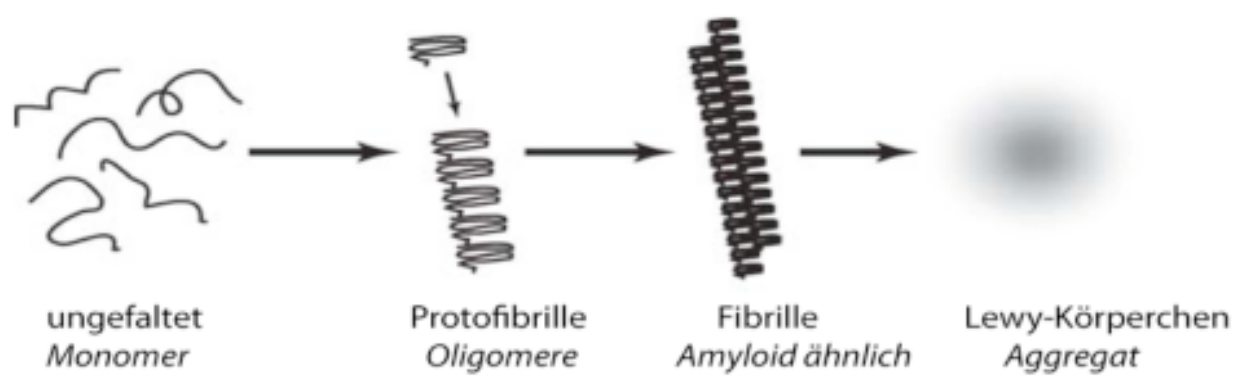

Abb. 3: Schematische Darstellung des Aggregationsmechanismus von alpha-Synuclein. Das physiologisch als Monomer vorliegende Protein wird dabei über oligomere Protofibrillen und amyloidähnliche Fibrillen zu Lewy Körpern aggregiert, welche sich dann im Neuron ablagern. Dabei scheinen die Oligomere die neurotoxisch Konformation darzustellen (modifizierte Version von Moore et al., 2005).

Obwohl Lewy Körper und Lewy Neuriten das pathologische Korrelat des IPS darstellen scheinen sie nicht wie lange angenommen (Braak et al. 2004) neurotoxische Eigenschaften zu besitzen. Zwar war in frühen transgenen Tiermodellen des IPS nur in Anwesenheit von Aggregaten ein Phänotyp sichtbar (Masliah et al., 2000; Feany et al., 2000), jedoch fand sich in vitro sowie in Hefezellen keine Korrelation zwischen Fibrillenbildung und Toxizität (Volles et al., 2007). Es wird vermutet, dass die Fibrillenbildung den Versuch der Zelle darstellt die toxischeren Konformationen zu eliminieren (Kahle et al., 2002). Mehrere Arbeiten liefern unabhängig voneinander Hinweise darauf, dass oligomere 
Konformationen von alpha-Synuclein neurotoxisch wirken (Goldberg et al., 2000; Giasson et al., 2001; El-Agnaf et al., 2006; Lansbury et al., 2006), wobei verschiedene Oligomersubtypen unterschiedliche toxische Eigenschaften aufweisen(Danzer et al., 2007). Zum Beispiel stören schnell oligomerisierende und fibrillationsverzögernde Mutationen von alphaSynuclein dopaminassozziertes Verhalten bei Würmern und Fliegen (Karpinar et al., 2009). Zusätzlich konnte durch lentivirale Überexpression oligomerisierender alpha-Synucleinmutationen ein erhöhter Zellverlust in der Substantia nigra gezeigt werden (Winner et al., submitted). Weiterhin zeigen Tiermodelle phänotypische Anzeichen des IPS ohne Aggregate zu produzieren (Kahle et al., 2001; Neumann et al., 2002; van der Putten et al., 2000; Nuber et al., 2007). Die A30P Mutation, welche bei den Betroffenen klinisch durch ein schnell progredientes Parkinsonsyndrom aufgefallen ist, zeigte bei in vitro Untersuchungen eine verstärkte Oligomerisierung des Proteins (Conway et al., 2000).

Neben diesem Einfluss der Oligomerisierung konnte gezeigt werden, dass auch der gestörte Abbau von alpha-Synuclein ursächlich für die Entwicklung des IPS ist. Die Inhibition des eiweißabbauenden, ProteasomUbiquitin Systems führt zur Bildung von Ubiquitin und alpha-Synuclein positiven Einschlüssen (Rideout et al., 2001). So könnte beim IPS die Proteinakkumulation durch eine Dysfunktion im proteasomalen Abbau (Shimura et al., 2000), durch posttranslationale Phosphorylierung oder durch Oxidation mitbestimmt werden (Fujiwara et al., 2002; Neumann, et al., 2002; Hasegawa et al., 2002). Zusätzlich spielen oxidativer Stress und mitochondriale Dysfunktion eine Rolle in der Pathogenese des IPS (Xu et al., 2002; Foley et al., 2000; Hsu et al., 2000).

Zusammenfassend können Störungen in Bildung, Aggregation und Abbau von alpha-Synuclein, induziert durch Mutationen, Überexpression oder Prozesse wie oxidatver Stress und mitochondriale Dysfunktion zur Entwicklung eines IPS beitragen. Dabei beeinflussen unterschiedliche Mutationen von alpha-Synuclein dessen Aggregationseigenschaften. 
Oligomere Formen von alpha-Synuclein haben dabei neurotoxisches Potential.

\section{Adulte Neurogenese}

Bereits 1969 wiesen Arbeiten auf sich teilende Neurone im adulten ZNS hin (Altman et al., 1969). Das von Cajal formulierte Dogma des nach der Embryonalphase unteilbaren neuronalen Anteils des adulten Gehirns ist heute längst widerlegt. Durch systemische Gabe von $\mathrm{C}^{14}$ Thymidin (Messier et al., 1958) und Bromodeoxiuridin (BrdU, Sano et al., 1965) und durch lokale Injektion von mit Reporterprotein markiertem Retrovirus (van Praag et al., 2002) waren Möglichkeiten geschaffen, neugebildete Neurone spezifisch nachzuweisen. Zusätzlich eröffnete die Etablierung von Doublecortin (DCX) als Marker für Neuroblasten die Möglichkeit, spezifisch neuronal determinierte Vorläuferzellen nachzuweisen (Nacher et al., 2001; Brown et al., 2003).

Bei Säugetieren sind zwei neurogene Zonen beschrieben worden (Kaplan et al., 1977). Die Subgranulärschicht des Gyrus Dentatus im Hippocampus stellt neue Neurone für die Granulärzellschicht des Gyrus Dentatus bereit. Die zweite neurogene Zone ist die an die Seitenventrikel angrenzende Subventrikulärzone welche GABAerge und dopaminerge Interneurone für das olfaktorische System liefert (Kempermann et al., 2004).

Der Begriff Neurogenese umfasst im Allgemeinen die Entstehung und Ausdifferenzierung von Nervenzellen und Nervensystemen. Dabei durchlaufen neu gebildete Nervenzellen unterschiedliche Stadien. Die wesentlichen Schritte, die Proliferation, die Migration und die Integration werden hier näher erläutert.

Zunächst wird aber kurz auf die Stammzelleigenschaften dieser Zellen eingegangen. 


\subsection{Adulte neurale Stammzellen}

Adulte neurale Stammzellen (=somatische Stammzellen des Gehirns; NSC) müssen definitionsgemäß folgende Bedingungen erfüllen:

1. Sie können aus dem adulten Gehirn isoliert werden

2. Sie können sich durch Proliferation kontinuierlich selbst erneuern, das heißt symmetrische aber auch asymmetrische Zellteilung ist möglich

3. Sie können alle Zellarten des ZNS bilden

(Zhao et al., 2008)

NSC teilen sich und differenzieren in Oligodendrozyten, Astrozyten und Neurone. Diese Stammzelleigenschaften konnten in vitro in Neurospheren und adherenten Monolayern bewiesen werden (Gage 2000).

\subsection{Adulte Neurogenese im Bulbus Olfaktorius}

Sowohl periglomeruläre als auch granuläre Neurone des Bulbus Olfaktorius werden im adulten Säugergehirn kontinuierlich neu gebildet (Bedard et al., 2004). Die SVZ der Seitenventrikel (unterhalb der Ependymschicht gelegen) ist in diesem System die neurogene Nische in der die neuralen Stammzellen proliferieren (Doetsch et al., 2003). Spezialisierte Astrozyten in der Subependymalzone bilden einen Pool sich teilender Zellen (Doetsch et al., 1999) mit charakteristischen Stammzellmarkern wie Nestin und Sox2 (Breunig et al., 2007). Zusätzlich lässt sich die Proliferation in der SVZ durch den Marker Proliferating cell nuclear antigen (PCNA) quantifizieren. Diese Zellen können durch asymetrische Zellteilung migrierende Neuroblasten bilden, welche zum rostralen migratorischen Strom (RMS) wandern (Lois et al., 1994; Lledo et al., 2006). Der RMS bietet den DCX positiven Neuroblasten die Möglichkeit tangential via sog. "chain migration" entlang von Astrozyten zu migrieren. Dabei werden sie im Gegensatz zur Neurogenese im embryonalen Hirn nicht von radialer Glia begleitet (Lledo et al., 2005). Durch den RMS erreichen die neu gebildeten Vorläuferzellen den Bulbus Olfaktorius und beginnen mit der tangentialen Wanderung in Richtung Bulbusperipherie. Ein Großteil der neuronalen Vorläufer differenziert in der 
Granulärzellschicht während der Rest mit einer zeitlichen Verzögerung die Glomerulärschicht erreicht (Petreanu et al., 2002).

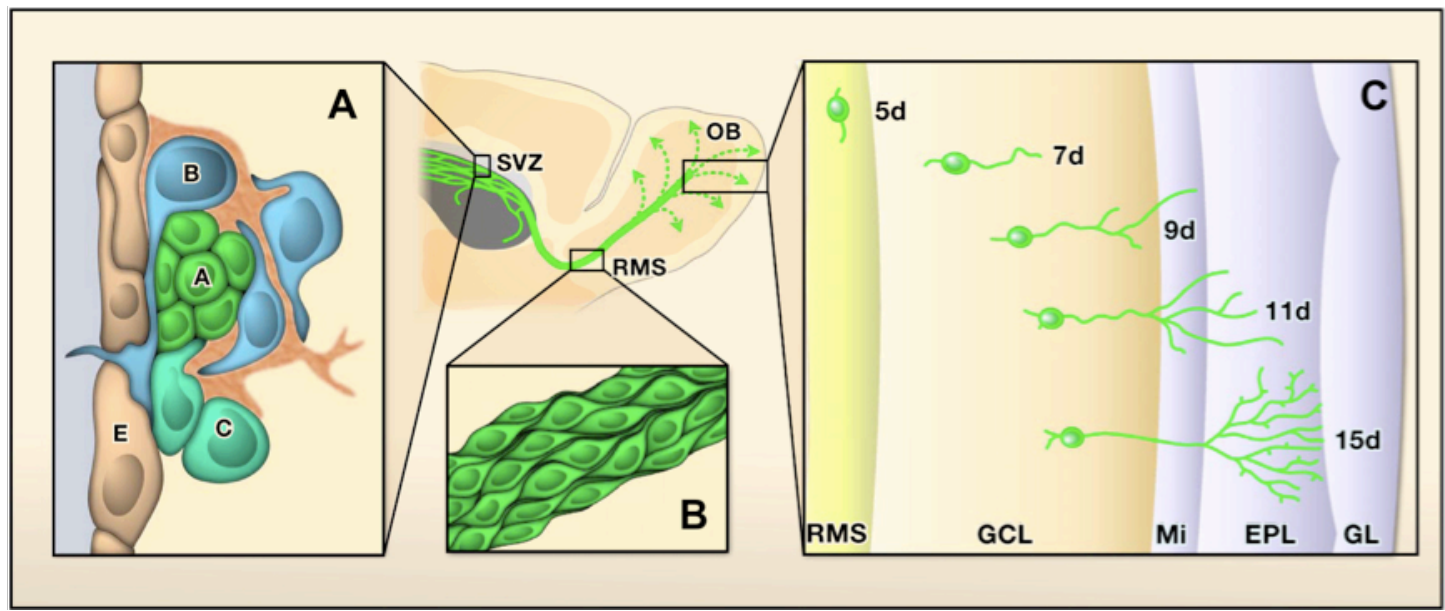

Abb. 4: Schematische Darstellung der adulten Neurogenese in der Subventrikulären Zone (SVZ, A), dem rostralen migratorischen Strom (RMS, B), und dem Bulbus Olfaktorius (OB, C). Einzelheiten s. Text. SVZ= Subventrikuläre Zone; RMS= rostraler migratorischer Strom; GCL= Granulärzellschicht; $\mathrm{Mi}=$ Mitralzellschicht; EPL= Externe Plexiforme Schicht; GL= Glomerulärzellschicht ; Bild aus Zhao et al.2008

Von den neugebildeten Periglomerulärzellen exprimieren bis zu $30 \%$ den mit dopaminergen Zellen assoziierten Marker Tyrosinhydroxylase (TH; Winner et al., 2002). Der gesamte Prozess der adulten Neurogenese dauert von Proliferation bis Integration ca. 30 Tage. Zwischen Tag 5 und 7 (Stadium 1) befinden sich die Vorläufer noch im RMS oder haben den Bulbus Olfaktorius gerade erreicht. Sie exprimieren die Vorläufermarker DCX und PSA-NCAM. Zwischen Tag 7 und 9 (Stadium 2) beginnt die Differenzierung dieser Neuroblasten welche von Tag 9-11 (Stadium 3) bis zum Tag 11-15 (Stadium 4) dauert. Die Neuroblasten beginnen dann den Marker für adulte Neurone neuronal nuclei antigen (NeuN) zu exprimieren während die DCX Expression langsam verschwindet. Ab Tag 15 zeigt der Dendritenbaum der jungen Neurone eine erwachsene Morphologie.

Der Prozess der Integration der neugebildeten Neurone lässt sich elektrophysiologisch in den Wochen 2-4 noch weiter differenzieren (Belluzzi et al., 2003). 4 Wochen nach BrdU Applikation exprimieren bis zu $98 \%$ der Zellen NeuN. Jedoch überleben nur $50 \%$ der Zellen länger als 3 Monate, verbleiben dann aber mindestens 19 Monate im Bulbus detektierbar. In dieser Zeit findet sich eine erhöhte Anzahl apoptotischer 
Zellen (Biebl et al., 2005) in der Granulärzellschicht wie auch in der periglomerulären Zone (Winner et al., 2002). Welchen Neuronentyp die integrierten Neurone bilden, konnte durch die Zuordnung zu transmitterassoziierten Enzymen und durch elektrophysiologische Untersuchungen festgestellt werden. Sowohl in der Granulärzellschicht als auch in der Periglomerulärzellschicht exprimiert die Mehrzahl der neuen Neurone GABA. In der Periglomerulärzellschicht enthalten bis zu $30 \%$ das Dopamin produzierende Enzym Tyrosinhydroxylase (Belluzzi et al., 2003; Carleton et al., 2003).

\section{Zusammenfassung der Publikation "Changes in adult olfactory bulb neurogenesis in mice expressing the A30P mutant form of alpha-Synuclein" (European Journal of Neuroscience, Vol. 29, pp. 879-890, 2009)}

Grundlage für die erfolgreiche Etablierung von Zellersatztherapien ist das Verständnis der Integration der neuen Nervenzellen im durch alphaSynuclein pathologisch veränderten Gehirn (siehe Abschnitt 2). In dieser Arbeit wird der oben beschriebene Prozess der adulten Neurogenese in einem regulierbaren $\mathrm{A} 30 \mathrm{P}$ alpha-Synuclein exprimierenden Tiermodell untersucht. A30P alpha-Synuclein wird unter der Kontrolle des Kalzium/Calmodulin-abhängigen Protein Kinase II alpha (CaMK)Promoters exprimiert. Dabei lässt sich die Expression von A30P alphaSynuclein durch die Gabe des Antibiotikums Doxycyclin unterdrücken. Es wurden folgende Hypothesen überprüft.

1) Die Expression von A30P alpha-Synuclein ist regulierbar

2) Die Expression von A30P alpha-Synuclein im Bulbus Olfaktorius reduziert die adulte Neurogenese im System SVZ/OB.

3) Suppression der alpha-Synuclein Expression beeinflusst die adulte Neurogenese im Bulbus Olfaktorius positiv. 


\subsection{Experimentelles Design}

Zur Überprüfung der Hypothesen wurde das regulierbare A30P alphaSynuclein exprimierende Mausmodell (im Folgenden A30P genannt) mit Kontrolltieren (im Folgenden control genannt) verglichen. Im Alter von 2 Monaten wurde bei einem Teil der A30P Tiere die Expression von alphaSynuclein durch Doxycyclin gestoppt (im Folgenden A30P+dox genannt). Um einen Einfluss von Doxycyclin auf die adulte Neurogenese auszuschließen erhielt ein Teil der Kontrolltiere ebenfalls ab dem zweiten Monat Doxycyclin (im Folgenden control+dox genannt).

Zur Untersuchung der adulten Neurogenese wurde den Tieren aller Gruppen im Alter von 3 Monaten Bromodeoxyuridin (BrdU) zur Markierung neu gebildeter Zellen injiziert. Im Alter von 4 Monaten, ein Zeitpunkt an dem die markierten neu gebildeten Neurone den Bulbus Olfaktorius erreicht haben und in das System integrieren, wurden die Tiere immunhistochemisch untersucht.

\subsection{Die Expression von A30P alpha-Synuclein ist regulierbar}

Alpha-Synuclein fand sich insbesondere in der Glomerulärzellschicht. Zusätzlich konnte es in der Granulärzellschicht sowie der plexiformen Schicht des Bulbus Olfaktorius zusammen mit typischen pathologischen Veränderungen wie Ubiquitinylierung, argyrophilen Neuriten und Zellkörpern detektiert werden. Dabei enthielten lediglich $4 \%$ der Neuroblasten in der Granulärzellschicht alpha-Synuclein während in der Glomerulärzellschicht bis zu $69 \%$ der neu gebildeten Zellen alphaSynuclein koexprimierten. In der A30P+dox Gruppe fand sich keine Expression von mutiertem alpha-Synuclein. Dies zeigt, dass die Expression von A30P alpha-Synuclein im Versuchszeitraum regulierbar ist und zu diesem Zeitpunkt noch keine permanente alpha-Synuclein Ablagerung im Bulbus Olfaktorius stattgefunden hat. 


\subsection{Die Expression von A30P alpha-Synuclein im Bulbus Olfaktorius reduziert die adulte Neurogenese im System SVZ/OB}

Zur Untersuchung der adulten Neurogenese wurde die Proliferation in der SVZ sowie die Neuroblastenzahl in der A30P Gruppe quantifiziert. Hier konnte kein Einfluss der alpha-Synuclein Expression festgestellt werden. Im Gegensatz dazu fand sich im Bulbus Olfaktorius eine signifikante Reduktion neu gebildeter Neurone in der Granulärzellschicht sowie neu gebildeter dopaminerger Neurone in der Glomerulärzellschicht. Parallel dazu lag eine erhöhte Anzahl apoptotischer Zellen vor.

Unter Expression von alpha-Synuclein ist somit die adulte Neurogenese im Bulbus Olfaktorius reduziert. Aufgrund dieser Ergebnisse sowie normaler Proliferationswerte und normaler Neuroblastenzahlen hat alpha-Synuclein vermutlich einen regulierenden Einfluss während der Integration der neuen Zellen.

\subsection{Suppression der alpha-Synuclein Expression beeinflusst die} adulte Neurogenese im Bulbus Olfaktorius

Das Unterdrücken der alpha-Synuclein Expression vor Analyse der Neurogenese beeinflusste die adulte Neurogenese positiv. So waren Neurogenese- und Apoptosewerte in der A30P+dox Gruppe vergleichbar mit denen der Kontrollgruppen. Dadurch konnte zum ersten Mal eine direkte zeitliche Korrelation zwischen alpha-Synuclein Expression und reduzierter Integration neuer Neurone sowie die prinzipielle Reversibilität dieses hemmenden Einflusses gezeigt werden. 


\section{Diskussion}

Mit Hilfe des regulierbaren A30P alpha-Synuclein exprimierenden Mausmodells konnte gezeigt werden, dass die adulte Neurogenese im Bulbus Olfaktorius durch die Expression von A30P alpha-Synuclein moduliert wird.

Die transiente Unterbrechung der alpha-Synuclein Expression zeigt, dass vor Analyse der Neurogenese keine permanente alpha-Synuclein Ablagerung im Bulbus Olfaktorius stattgefunden hat und es konnte zum ersten Mal eine direkte Korrelation zwischen pathologischem alphaSynuclein und der Regulation der adulten Neurogenese gezeigt werden. Der Einfluss von alpha-Synuclein spielt dabei insbesondere bei der Integration der neuen Neurone eine Rolle. In dem hier untersuchten Modell können somit alle drei formulierten Hypothesen angenommen werden.

\subsection{Die A30P alpha-Synuclein Maus als Modellsystem früher alpha- Synuclein assoziierter Pathologie}

Symptomenkomplexe welche eine prämotorische Diagnose des IPS wahrscheinlicher machen, werden aktuell definiert (Siderowf et al., 2006; Siderowf et al., 2008). In diesem Symptomenkomplex nimmt die Anosmie als häufiger, klinisch leicht detektierbarer und früh auftretender Surrogatmarker eine wichtige Stellung ein (Siderowf et al., 2005). Damit korrelieren früh auftretende pathologische Veränderungen im olfaktorischen System (Braak et al., 2003). Im hier vorgestellten Mausmodell wird A30P alpha-Synuclein zu 80\% im olfaktorischen System exprimiert und es finden sich zusätzliche Charakteristika alpha-Synuclein assoziierter Pathologie, wie Ubiquitinylierung (Spillantini et al., 1997; Neumann et al., 2002; Braak et al., 1999), welche bereits in anderen Tiermodellen wie auch in zellkulturbasierten Systemen für A30P alphaSynuclein beschrieben wurden (Kahle et al., 2000; Schneider et al., 2007). Mausmodelle die A30P alpha-Synuclein unter der Kontrolle des Thy-1 Promoters exprimieren, zeigen eine intrazelluläre Akkumulation von phosphoryliertem alpha-Synuclein welches mit einer Verschlechterung der 
motorischen, kognitiven und olfaktorischen Leistung einhergeht (Fleming et al., 2004; Freichel et al., 2007). Das in diesen Tiermodellen wie auch in zellkulturbasierten Systemen (Schneider et al., 2007) gefundene, typische intrazelluläre Verteilungsmuster von A30P alpha-Synuclein findet sich auch in dem hier vorgestellten A30P Mausmodell. Zum Untersuchungszeitpunkt findet sich nur wenig alpha-Synuclein in anderen Regionen des Gehirns und die alpha-Synuclein Pathologie ist zu diesem Zeitpunkt vollständig reversibel. Für ein motorisches Defizit fanden sich zum Untersuchungszeitpunkt keine auffälligen Verhaltensweisen und ein olfaktorisches Defizit konnte nicht festgestellt werden.

So kann die A30P Maus als ein pathologisches Modell früher, präsymptomatischer alpha-Synuclein Pathologie betrachtet werden. Weitere Versuche sind notwendig um zu klären, ob sich eine progrediente Pathologie sowie ein olfaktorisches Defizit zu einem späteren Zeitpunkt entwickeln. Die Regulierbarkeit ermöglicht eine exakte chronologische Charakterisierung der alpha-Synuclein Effekte, insbesondere in den beim IPS früh befallenen Hirnregionen. Diese Regionen, wie auch die Untersuchung früher zellulärer Veränderungen rücken immer stärker ins Zentrum der pathogenetischen Betrachtung des IPS.

\subsection{Einfluss von A30P alpha-Synuclein auf die zelluläre Plastizität}

Der progressive Charakter der A30P Mutation von alpha-Synuclein beruht vermutlich auf ihren schnell oligomerisierenden Eigenschaften (Conway et al., 2000). Die permanente Akkumulation von alpha-Synuclein in Form von Fibrillen und Lewy Körpern korreliert nicht mit Neurotoxizität (Karpinar et al., 2009; Chen et al., 2005), stellt aber den pathologisch detektierbaren Endpunkt des Aggregationsprozesses dar (Braak et al., 2003; Desplats et al., 2009). Obwohl Neurodegeneration beim IPS ein chronischer und langsam ablaufender Prozess ist, weisen mehrere Daten auf einen direkten Einfluss von alpha-Synuclein und dessen Mutationen auf das Überleben neuronaler Vorläuferzellen in vitro hin (Xu et al., 2002,; 
Schneider et al., 2007). Proliferation, Differenzierung und Integration stellen hierfür vulnerable Zeitpunkte dar (Nuber et al., 2008).

Die adulte Neurogenese ist in Mausmodellen des IPS reduziert (Winner et al., 2004; Winner et al., 2008). Unklar blieb dabei jedoch inwiefern alphaSynuclein direkt oder die sekundären Folgen der alpha-Synuclein Überexpression in diesen Mausmodellen für den Effekt auf die neu gebildeten Neurone zuständig waren. Durch die Regulierbarkeit konnte hier zum ersten Mal eine direkte Korrelation zwischen A30P alphaSynuclein und reduzierter Neurogenese gezeigt werden. Diese Reduktion verhält sich umgekehrt proportional zur exprimierten und zur mit jungen Neuronen koexprimierten alpha-Synuclein Menge. So ist die adulte Neurogenese in der Glomerulärzellschicht, welche die stärkste alphaSynuclein Expression und Koexpression mit neuen Neuronen (69\%) aufweist, stärker betroffen als die Granulärzellschicht, die wenig alphaSynuclein Expression und Koexpression (4\%) zeigt. Alpha-Synuclein findet sich erst spät in Neuroblasten, nämlich ab dem Erreichen des Bulbus Olfaktorius. Der Grund hierfür liegt am wahrscheinlichsten in der späten Induktion der CaMK Expression und damit auch der Expression des Transgens in unserem Modell (Faison et al., 2002). Ob die beobachtete Reduktion der adulten Neurogenese auf zellintrinsischen oder extrinsischen Folgen der alpha-Synuclein Expression beruht, oder ob alpha-Synuclein wie beschrieben eventuell über transzelluläre Weitergabe (Desplats et al., 2009) die integrierenden neuen Neurone erreicht und beeinflusst, bleibt hier unklar.

Jedoch zeigen unsere Experimente eindrucksvoll einen sehr unmittelbaren Effekt von alpha-Synuclein auf die zelluläre Plastizität in vivo. So findet sich eine Reduktion der adulten Neurogenese nur bei paralleler Expression von alpha-Synuclein. 


\subsection{Modulation der alpha-Synuclein Expression und zellersatzbasierte Therapieformen des IPS}

Das Überleben transplantierter Zellen ist essentiell für die Effektivität zellersatzbasierter Therapieformen (Hagell et al., 2001). Das Auftreten von Lewy Körpern im transplantierten Hirngewebe in Studien an IPS Patienten (Li et al., 2008; Kordower et al., 2008) zeigt, dass transplantiertes Gewebe scheinbar von den neurodegenerativen Prozessen des umliegenden Gewebes beeinflusst wird (Braak et al., 2008). Die in diesen Studien genannte Lewy ähnliche Pathologie fand sich in 11 bis 16 Jahre altem transplantierten Gewebe (Kordower et al., 2008). Jedoch kann bei einer Menge von 4\% Lewy Pathologie von einer geringen klinischen Relevanz ausgegangen werden. Zusätzlich korreliert Fibrillenbildung und die Formation von Lewy Körperchen nicht mit Neurotoxizität (Karpinar et al., 2009; Chen et al., 2005). Die für das Zellersatzgewebe schädlichen Prozesse könnten theoretisch auch früher das Überleben neuer Zellen stören. So zeigen wir in der hier vorgestellten Arbeit einen sehr unmittelbaren Effekt von alpha-Synuclein auf die zelluläre Integrität. In diesem pathologischen Modell früher, präsymptomatischer alphaSynuclein Pathologie findet sich eine Reduktion der adulten Neurogenese nur bei gleichzeitiger Expression von alpha-Synuclein. Ein vulnerabler Zeitpunkt ist hierbei die Integration der neuen Neurone. Die Übertragbarkeit dieser Resultate und Schlussfolgerungen auf andere Transplantationsergebnisse ist fraglich, eine Überprüfung ist aber im olfaktorischen System dieses Mausmodells und in einem anderen Mausmodell (Nuber et al., 2008) durch die Regulierbarkeit möglich.

Für eine endogene Zellersatztherapie folgt hieraus zunächst ein weiteres Hindernis im Bezug auf das Überleben neuer Neurone. Die Modulation der adulten Neurogenese durch Unterdrückung der alpha-Synuclein Expression zeigt aber auch die positive Beeinflussbarkeit der Integrationsfähigkeit der neuen Neurone. So könnte ein die alphaSynuclein Pathologie beeinflussender neuroprotektiver Ansatz eine, zu einem frühen Zeitpunkt begonnene, endogene Zellersatztherapie komplementär unterstützen und das Überleben neuer Zellen fördern. Bei 
früher Diagnose und Therapie ließe sich so eventuell eine Krankheitsprogression verhindern. 


\section{Literaturverzeichnis}

Abeliovich, A., Y. Schmitz, et al. (2000). "Mice lacking alpha-synuclein display functional deficits in the nigrostriatal dopamine system." Neuron 25(1): 239-52.

Altman, J. (1969). "Autoradiographic and histological studies of postnatal neurogenesis. IV. Cell proliferation and migration in the anterior forebrain, with special reference to persisting neurogenesis in the olfactory bulb." $\mathrm{J}$ Comp Neurol 137(4): 433-57

Bedard, A. (2004). "Evidence of newly generated neurons in the human olfactory bulb." Developmental Brain Research 151(1-2): 159-168.

Belluzzi, O., M. Benedusi, et al. (2003). "Electrophysiological differentiation of new neurons in the olfactory bulb." J Neurosci 23(32): 10411-8.

Biebl, M., B. Winner, et al. (2005). "Caspase inhibition decreases cell death in regions of adult neurogenesis." Neuroreport 16(11): 1147-50.

Braak, H. and K. Del Tredici (2008). "Assessing fetal nerve cell grafts in Parkinson's disease." Nat Med.

Braak, H., K. Del Tredici, et al. (2003). "Staging of brain pathology related to sporadic Parkinson's disease." Neurobiol Aging 24(2): 197-211.

Braak, H., E. Ghebremedhin, et al. (2004). "Stages in the development of Parkinson's disease-related pathology." Cell Tissue Res 318(1): 121-134.

Breunig, J. J., J. I. Arellano, et al. (2007). "Everything that glitters isn't gold: a critical review of postnatal neural precursor analyses." Cell Stem Cell 1(6): 612-27. 
Brown, J. P., S. Couillard-Despres, et al. (2003). "Transient expression of doublecortin during adult neurogenesis." J Comp Neurol 467(1): 1-10.

Brundin, P., J.-Y. Li, et al. (2008). "Research in motion: the enigma of Parkinson's disease pathology spread." Nat Rev Neurosci 9(10): 741-5.

Carleton, A., L. T. Petreanu, et al. (2003). "Becoming a new neuron in the adult olfactory bulb." Nat Neurosci 6(5): 507-18.

Conway, K. A., S. J. Lee, et al. (2000). "Acceleration of oligomerization, not fibrillization, is a shared property of both alpha-synuclein mutations linked to early-onset Parkinson's disease: implications for pathogenesis and therapy." Proc Natl Acad Sci USA 97(2): 571-6.

Conway, K. A., J. C. Rochet, et al. (2001). "Kinetic stabilization of the alpha-synuclein protofibril by a dopamine-alpha-synuclein adduct." Science 294(5545): 1346-9.

Curtis (2007). "Human neuroblasts migrate to the olfactory bulb via a lateral ventricular extension." Science 315(5816): 1243-9.

Danzer, K. M., D. Haasen, et al. (2007). "Different species of alphasynuclein oligomers induce calcium influx and seeding." J Neurosci 27(34): 9220-32.

Del Tredici, K., U. Rüb, et al. (2002). "Where does parkinson disease pathology begin in the brain?" J Neuropathol Exp Neurol 61(5): 413-26.

Desplats, P., H.-J. Lee, et al. (2009). "Inclusion formation and neuronal cell death through neuron-to-neuron transmission of alpha-synuclein." Proc Natl Acad Sci USA 106(31): 13010-5. 
Doetsch, F. (2003). "A niche for adult neural stem cells." Curr Opin Genet Dev 13(5): 543-50.

Doetsch, F., I. Caillé, et al. (1999). "Subventricular zone astrocytes are neural stem cells in the adult mammalian brain." Cell 97(6): 703-16.

Duvoisin, R. C. and L. I. Golbe (1995). "Kindreds of dominantly inherited Parkinson's disease: keys to the riddle." Ann Neurol 38(3): 355-6.

El-Agnaf, O. M. A., S. A. Salem, et al. (2006). "Detection of oligomeric forms of alpha-synuclein protein in human plasma as a potential biomarker for Parkinson's disease." FASEB J 20(3): 419-25.

Eriksson, P. S., E. Perfilieva, et al. (1998). "Neurogenesis in the adult human hippocampus." Nat Med 4(11): 1313-7.

Faison, M. O., E. F. Perozzi, et al. (2002). "Axonal localization of delta Ca2+/calmodulin-dependent protein kinase II in developing P19 neurons." Int J Dev Neurosci 20(8): 585-92.

Farrer, M. J. (2006). "Genetics of Parkinson disease: paradigm shifts and future prospects." Nat Rev Genet 7(4): 306-318.

Feany, M. B. and W. W. Bender (2000). "A Drosophila model of Parkinson's disease." Nature 404(6776): 394-8.

Fleming, S. M., J. Salcedo, et al. (2004). "Early and progressive sensorimotor anomalies in mice overexpressing wild-type human alphasynuclein." J Neurosci 24(42): 9434-40. 
Foley, P. and P. Riederer (2000). "Influence of neurotoxins and oxidative stress on the onset and progression of Parkinson's disease." J Neurol 247 Suppl 2: II82-94.

Forno, L. S. (1996). "Neuropathology of Parkinson's disease." J Neuropathol Exp Neurol 55(3): 259-72.

Freed, C. R., P. E. Greene, et al. (2001). "Transplantation of embryonic dopamine neurons for severe Parkinson's disease." N Engl J Med 344(10): 710-9.

Freichel, C., M. Neumann, et al. (2007). "Age-dependent cognitive decline and amygdala pathology in alpha-synuclein transgenic mice." Neurobiol Aging 28(9): 1421-35.

Fujiwara, H., M. Hasegawa, et al. (2002). "alpha-Synuclein is phosphorylated in synucleinopathy lesions." Nat Cell Biol 4(2): 160-4.

Gage, F. H. (2000). "Mammalian neural stem cells." Science 287(5457): 1433-8.

Giasson, B. I., I. V. Murray, et al. (2001). "A hydrophobic stretch of 12 amino acid residues in the middle of alpha-synuclein is essential for filament assembly." J Biol Chem 276(4): 2380-6.

Goldberg, M. S. and P. T. Lansbury (2000). "Is there a cause-and-effect relationship between alpha-synuclein fibrillization and Parkinson's disease?" Nat Cell Biol 2(7): E115-9.

Hagell, P. and P. Brundin (2001). "Cell survival and clinical outcome following intrastriatal transplantation in Parkinson disease." J Neuropathol Exp Neurol 60(8): 741-52. 
Hasegawa, M., H. Fujiwara, et al. (2002). "Phosphorylated alpha-synuclein is ubiquitinated in alpha-synucleinopathy lesions." J Biol Chem 277(50): 49071-6.

Hockemeyer, D., F. Soldner, et al. (2008). "A drug-inducible system for direct reprogramming of human somatic cells to pluripotency." Cell Stem Cell 3(3): 346-53.

Hsu, L. J., Y. Sagara, et al. (2000). "alpha-synuclein promotes mitochondrial deficit and oxidative stress." Am J Pathol 157(2): 401-10.

Investigators, P. S. G. C. C. (2009). "Long-term effect of initiating pramipexole vs levodopa in early Parkinson disease." Arch Neurol 66(5): 563-70.

Kahle, P. J., M. Neumann, et al. (2000). "Subcellular localization of wildtype and Parkinson's disease-associated mutant alpha -synuclein in human and transgenic mouse brain." J Neurosci 20(17): 6365-73.

Kaplan, M. S. and J. W. Hinds (1977). "Neurogenesis in the adult rat: electron microscopic analysis of light radioautographs." Science 197(4308): 1092-4.

Karpinar, D. P., M. B. G. Balija, et al. (2009). "Pre-fibrillar \&alpha;synuclein variants with impaired \&beta;-structure increase neurotoxicity in Parkinson\&apos;s disease models." 1-13.

Kempermann, G., L. Wiskott, et al. (2004). "Functional significance of adult neurogenesis." Curr Opin Neurobiol 14(2): 186-91. 
Kiskinis, E. and K. Eggan (2010). "Progress toward the clinical application of patient-specific pluripotent stem cells." J Clin Invest 120(1): 51-9.

Kordower, J. H., Y. Chu, et al. (2008). "Transplanted dopaminergic neurons develop PD pathologic changes: a second case report." Mov Disord 23(16): 2303-6.

Krüger, R., W. Kuhn, et al. (1998). "Ala30Pro mutation in the gene encoding alpha-synuclein in Parkinson's disease." Nat Genet 18(2): 106-8.

Langston, J. W. (2006). "The Parkinson's complex: parkinsonism is just the tip of the iceberg." Ann Neurol 59(4): 591-6.

Lansbury, P. T. and H. A. Lashuel (2006). "A century-old debate on protein aggregation and neurodegeneration enters the clinic." Nature 443(7113): 774-9.

Li, J.-Y., E. Englund, et al. (2008). "Lewy bodies in grafted neurons in subjects with Parkinson's disease suggest host-to-graft disease propagation." Nat Med 14(5): 501-3.

Lindvall, O., P. Brundin, et al. (1990). "Grafts of fetal dopamine neurons survive and improve motor function in Parkinson's disease." Science 247(4942): 574-7.

Lindvall, O. and Z. Kokaia (2010). "Stem cells in human neurodegenerative disorders--time for clinical translation?" J Clin Invest 120(1): 29-40.

Lledo, P.-M., M. Alonso, et al. (2006). "Adult neurogenesis and functional plasticity in neuronal circuits." Nat Rev Neurosci 7(3): 179-93. 
Lledo, P.-M. and A. Saghatelyan (2005). "Integrating new neurons into the adult olfactory bulb: joining the network, life-death decisions, and the effects of sensory experience." Trends Neurosci 28(5): 248-54.

Lois, C. and A. Alvarez-Buylla (1994). "Long-distance neuronal migration in the adult mammalian brain." Science 264(5162): 1145-8.

Maroteaux, L., J. T. Campanelli, et al. (1988). "Synuclein: a neuron-specific protein localized to the nucleus and presynaptic nerve terminal." $\mathrm{J}$ Neurosci 8(8): 2804-15.

Masliah, E., E. Rockenstein, et al. (2000). "Dopaminergic loss and inclusion body formation in alpha-synuclein mice: implications for neurodegenerative disorders." Science 287(5456): 1265-9.

Mendez, I., A. Viñuela, et al. (2008). "Dopamine neurons implanted into people with Parkinson's disease survive without pathology for 14 years." Nat Med 14(5): 507-9.

MESSIER, B., C. P. LEBLOND, et al. (1958). "Presence of DNA synthesis and mitosis in the brain of young adult mice." Exp Cell Res 14(1): 224-6.

Mohapel, P., H. Frielingsdorf, et al. (2005). "Platelet-derived growth factor (PDGF-BB) and brain-derived neurotrophic factor (BDNF) induce striatal neurogenesis in adult rats with 6-hydroxydopamine lesions." Neuroscience 132(3): 767-76.

Moore, D. J., A. B. West, et al. (2005). "Molecular pathophysiology of Parkinson's disease." Annu Rev Neurosci 28: 57-87.

Nacher, J., C. Crespo, et al. (2001). "Doublecortin expression in the adult rat telencephalon." Eur J Neurosci 14(4): 629-44. 
Neumann, M., P. J. Kahle, et al. (2002). "Misfolded proteinase K-resistant hyperphosphorylated alpha-synuclein in aged transgenic mice with locomotor deterioration and in human alpha-synucleinopathies." J Clin Invest 110(10): 1429-39.

Nuber, S., E. Petrasch-Parwez, et al. (2008). "Neurodegeneration and motor dysfunction in a conditional model of Parkinson's disease." $\mathrm{J}$ Neurosci 28(10): 2471-84.

Olanow, C. W., M. B. Stern, et al. (2009). "The scientific and clinical basis for the treatment of Parkinson disease (2009)." Neurology 72(Iss 21, Supp 4): S1-S136.

Park, I.-H., N. Arora, et al. (2008). "Disease-specific induced pluripotent stem cells." Cell 134(5): 877-86.

Pencea, V., K. D. Bingaman, et al. (2001). "Infusion of brain-derived neurotrophic factor into the lateral ventricle of the adult rat leads to new neurons in the parenchyma of the striatum, septum, thalamus, and hypothalamus." J Neurosci 21(17): 6706-17.

Perez, R. G., J. C. Waymire, et al. (2002). "A role for alpha-synuclein in the regulation of dopamine biosynthesis." J Neurosci 22(8): 3090-9.

Petreanu, L. and A. Alvarez-Buylla (2002). "Maturation and death of adultborn olfactory bulb granule neurons: role of olfaction." J Neurosci 22(14): 6106-13.

Polymeropoulos, M. H., J. J. Higgins, et al. (1996). "Mapping of a gene for Parkinson's disease to chromosome 4q21-q23." Science 274(5290): 11979. 
Ponsen, M. M., D. Stoffers, et al. (2004). "Idiopathic hyposmia as a preclinical sign of Parkinson's disease." Ann Neurol 56(2): 173-81.

Rideout, H. J., K. E. Larsen, et al. (2001). "Proteasomal inhibition leads to formation of ubiquitin/alpha-synuclein-immunoreactive inclusions in PC12 cells." J Neurochem 78(4): 899-908.

Rubinsztein, D. C. (2006). "The roles of intracellular protein-degradation pathways in neurodegeneration." Nature 443(7113): 780-6.

Sanai, N., A. D. Tramontin, et al. (2004). "Unique astrocyte ribbon in adult human brain contains neural stem cells but lacks chain migration." Nature 427(6976): 740-4.

Sandmann-Keil et al. Alpha-synuclein immunoreactive Lewy bodies and Lewy neurites in Parkinson's disease are detectable by an advanced silverstaining technique. Acta Neuropathol (1999) vol. 98 (5) pp. 461-4

Sano, K., F. Sato, et al. (1965). "Experimental and clinical studies of radiosensitizers in brain tumors, with special reference to BUdRantimetabolite continuous regional infusion-radiation therapy (BAR therapy)." Neurol Med Chir (Tokyo) 7: 51-72.

Schneider, B. L., C. R. Seehus, et al. (2007). "Over-expression of alphasynuclein in human neural progenitors leads to specific changes in fate and differentiation." Hum Mol Genet 16(6): 651-66.

Shimura, H., N. Hattori, et al. (2000). "Familial Parkinson disease gene product, parkin, is a ubiquitin-protein ligase." Nat Genet 25(3): 302-5. 
Siderowf, A., A. Newberg, et al. (2005). "[99mTc]TRODAT-1 SPECT imaging correlates with odor identification in early Parkinson disease." Neurology 64(10): 1716-20.

Siderowf, A. and M. B. Stern (2006). "Preclinical diagnosis of Parkinson's disease: are we there yet?" Curr Neurol Neurosci Rep 6(4): 295-301.

Siderowf, A. and M. B. Stern (2008). "Premotor Parkinson's disease: clinical features, detection, and prospects for treatment." Ann Neurol 64 Suppl 2: S139-47.

Soldner, F., D. Hockemeyer, et al. (2009). "Parkinson•s Disease PatientDerived Induced Pluripotent Stem Cells Free of Viral Reprogramming Factors." Cell 136(5): 964-977.

Spillantini, M. G., M. L. Schmidt, et al. (1997). "Alpha-synuclein in Lewy bodies." Nature 388(6645): 839-40.

Svendsen, C. (2008). "Stem cells and Parkinson's disease: toward a treatment, not a cure." Cell Stem Cell 2(5): 412-3.

Svendsen, C. N., M. A. Caldwell, et al. (1997). "Long-term survival of human central nervous system progenitor cells transplanted into a rat model of Parkinson's disease." Exp Neurol 148(1): 135-46.

Takahashi et al. Induction of Pluripotent Stem Cells from Adult Human Fibroblasts by Defined Factors. Cell (2007) vol. 131 (5) pp. 861-872

van Der Putten, H., K. H. Wiederhold, et al. (2000). "Neuropathology in mice expressing human alpha-synuclein." J Neurosci 20(16): 6021-9. 
Van Praag, H., A. F. Schinder, et al. (2002). "Functional neurogenesis in the adult hippocampus." Nature 415(6875): 1030-4.

van Rooijen, B. D., K. A. van Leijenhorst-Groener, et al. (2009). "Tryptophan fluorescence reveals structural features of alpha-synuclein oligomers." J Mol Biol 394(5): 826-33.

Volles, M. J. and P. T. Lansbury (2007). "Relationships between the sequence of alpha-synuclein and its membrane affinity, fibrillization propensity, and yeast toxicity." J Mol Biol 366(5): 1510-22.

Wernig, M., J.-P. Zhao, et al. (2008). "Neurons derived from reprogrammed fibroblasts functionally integrate into the fetal brain and improve symptoms of rats with Parkinson's disease." Proc Natl Acad Sci USA 105(15): 585661.

Wijeyekoon, R. and R. A. Barker (2009). "Cell replacement therapy for Parkinson's disease." Biochim Biophys Acta 1792(7): 688-702.

Winner, B., C. M. Cooper-Kuhn, et al. (2002). "Long-term survival and cell death of newly generated neurons in the adult rat olfactory bulb." Eur $\mathrm{J}$ Neurosci 16(9): 1681-9.

Winner, B., P. Desplats, et al. (2009). "Dopamine receptor activation promotes adult neurogenesis in an acute Parkinson model." Exp Neurol 219(2): 543-52.

Winner, B., D. C. Lie, et al. (2004). "Human wild-type alpha-synuclein impairs neurogenesis." J Neuropathol Exp Neurol 63(11): 1155-66. 
Winner, B., E. Rockenstein, et al. (2008). "Mutant alpha-synuclein exacerbates age-related decrease of neurogenesis." Neurobiol Aging Volume 29(Issue 6): 913-925.

Xu, J., S.-Y. Kao, et al. (2002). "Dopamine-dependent neurotoxicity of alpha-synuclein: a mechanism for selective neurodegeneration in Parkinson disease." Nat Med 8(6): 600-6.

Zarranz et al. The new mutation, E46K, of alpha-synuclein causes Parkinson and Lewy body dementia. Ann Neurol (2004) vol. 55 (2) pp. 16473

Zhao, C., W. Deng, et al. (2008). "Mechanisms and functional implications of adult neurogenesis." Cell 132(4): 645-60. 


\section{Manuskript: Changes in adult olfactory bulb neurogenesis in mice expressing the A30P mutant form of alpha-Synuclein}

Franz Marxreiter ${ }^{1}$ \#, Silke Nuber ${ }^{2}$ \#, Mahesh Kandasamy ${ }^{1}$, Jochen Klucken ${ }^{1}$, Robert Aigner ${ }^{1}$, Ralf Burgmayer ${ }^{1}$, Sebastien Couillard-Despres ${ }^{1}$, Olaf Riess $^{2}$, Jürgen Winkler ${ }^{3,4}$, and Beate Winner ${ }^{1^{*}}$

\footnotetext{
${ }^{1}$ Department of Neurology, University of Regensburg, Universitätsstraße 84, 93053 Regensburg, Germany

${ }^{2}$ Department of Medical Genetics, University of Tübingen, Calwerstrasse 7, 72076 Tübingen, Germany

${ }^{3}$ Department of Neurosciences, University of California, San Diego 9500 Gilman Drive, La Jolla, CA 920930662, USA

${ }^{4}$ Division of Molecular Neurology, University of Erlangen-Nuernberg, Schwabachanlage 6, 91054 Erlangen, Germany
}

\# Franz Marxreiter and Silke Nuber contributed equally to this work "current address: Laboratory of Genetics, The Salk Institute for Biological Studies, 10010 North Torrey Pines Road, La Jolla, California, 92037-1099, USA

Key words: neural progenitor cells, Parkinson disease, synucleinopathies, subventricular zone, adult neurogenesis 


\title{
Changes in adult olfactory bulb neurogenesis in mice expressing the A30P mutant form of alpha-synuclein
}

\author{
Franz Marxreiter, ${ }^{1, *}$ Silke Nuber, ${ }^{2, *}$ Mahesh Kandasamy, ${ }^{1}$ Jochen Klucken, ${ }^{1,4}$ Robert Aigner, ${ }^{1,4}$ Ralf Burgmayer, ${ }^{1}$ \\ Sebastien Couillard-Despres, ${ }^{1}$ Olaf Riess, ${ }^{2}$ Jürgen Winkler ${ }^{3,4}$ and Beate Winner ${ }^{1, \dagger}$ \\ ${ }^{1}$ Department of Neurology, University of Regensburg, Universitätsstraße 84, 93053 Regensburg, Germany \\ ${ }^{2}$ Department of Medical Genetics, University of Tübingen, Tübingen, Germany \\ ${ }^{3}$ Department of Neurosciences, University of California, La Jolla, CA, USA \\ ${ }^{4}$ Division of Molecular Neurology, University of Erlangen, Erlangen, Germany
}

Keywords: adult neurogenesis, neural progenitor cells, Parkinson disease, subventricular zone, synucleinopathies

\begin{abstract}
In familial and sporadic forms of Parkinson's disease (PD), alpha-synuclein pathology is present in the brain stem nuclei and olfactory bulb (OB) long before Lewy bodies are detected in the substantia nigra. The OB is an active region of adult neurogenesis, where newly generated neurons physiologically integrate. While accumulation of wild-type alpha-synuclein is one of the pathogenic hallmarks of non-genetic forms of PD, the A30P alpha-synuclein mutation results in an earlier disease onset and a severe clinical phenotype. Here, we study the regulation of adult neurogenesis in the subventricular zone (SVZ)/OB system in a tetracyclinesuppressive (tet-off) transgenic model of synucleinopathies, expressing human mutant A30P alpha-synuclein under the control of the calcium/calmodulin-dependent protein kinase II alpha (CaMK) promoter. In A30P transgenic mice alpha-synuclein was abundant at the site of integration in the glomerular cell layer of the OB. Without changes in proliferation in the SVZ, significantly fewer newly generated neurons were observed in the $\mathrm{OB}$ granule cell and glomerular layers of A30P transgenic mice than in controls, most probably due to increased cell death. By tetracycline-dependent abrogation of A3OP alpha-synuclein expression, OB neurogenesis and programmed cell death was restored to control levels. Our results indicate that, using A30P conditional (tet-off) mice, A30P alpha-synuclein has a negative impact on olfactory neurogenesis and suppression of A30P alpha-synuclein enhances survival of newly generated neurons. This finding suggests that interfering with alpha-synuclein pathology can rescue newly generated neurons, possibly leading to new targets for therapeutic interventions in synucleinopathies.
\end{abstract}

\section{Introduction}

Instead of being restricted to nigrostriatal pathology, synucleinopathies are now considered to be multisystem disorders that severely damage predisposed neural cell types in multiple regions of the central nervous system. Physiologically unfolded alpha-synuclein monomers aggregate to form fibrils in Parkinson's disease (PD; Conway et al., 1998). Fibrillar alpha-synuclein is the major constituent of Lewy bodies, one of the pathological hallmarks in PD (Spillantini et al., 1997). Controversy remains about which alpha-synuclein conformation, prefibrillar oligomeric or fibrillar, is the toxic culprit (Giasson et al., 2001). The mutant human A30P alpha-synuclein (A30P) point mutation accelerates the transition of the protein into oligomeric forms, specifically into spherical protofibrils (Conway et al., 2000). Overexpression of $\mathrm{A} 30 \mathrm{P}$ forms of alpha-synuclein reduced cell numbers of human embryonic stem cell-derived dopaminergic neurons to a greater extent than wild-type alpha-synuclein (Schneider et al.,

Correspondence: Dr B. Winner, at ${ }^{\dagger}$ present address below.

E-mail: beate.winner@klinik.uni-regensburg.de

*F.M. and S.N. contributed equally to this work.

'Present address: Laboratory of Genetics, The Salk Institute for Biological Studies, 10010 North Torrey Pines Road, La Jolla, California, 92037-1099, USA.

Received 10 April 2008, revised 17 December 2008, accepted 28 December 2008
2007). This rare mutation leads to an autosomal dominant form of PD, originally described in a German pedigree that is characterized by an early onset and accelerated progression (Kruger et al., 1998).

Braak staging of Lewy pathology in brains of sporadic PD patients revealed that brainstem and olfactory structures are affected early on in the disease (Braak et al., 2003). First-degree relatives of PD patients have an increased risk of PD, accompanied by olfactory dysfunction (Montgomery et al., 2000). In addition, olfactory dysfunction is a surrogate marker for subsequent PD- associated motor impairment (Siderowf et al., 2005). In the olfactory bulb (OB), adult neurogenesis continuously provides new interneurons for the granular and the glomerular cell layers, among them dopaminergic neurons. In rodents and humans new cells are continuously generated in the subventricular zone (SVZ) of the lateral ventricle (Doetsch et al., 1999; Sanai et al., 2004) and migrate through the rostral migratory stream (RMS) to the OB (Lois et al., 1996; Curtis et al., 2007), where they differentiate into GABAergic and/or dopaminergic interneurons and functionally integrate (Winner et al., 2002; Carleton et al., 2003). We have previously shown that wild-type alpha-synuclein-overexpressing mice show a reduction in olfactory neurogenesis (Winner et al., 2004, 2007).

The effects of the $\mathrm{A} 30 \mathrm{P}$ mutation on $\mathrm{OB}$ neurogenesis are presently unknown. To investigate how neurogenesis is affected by A30P alpha-synuclein and whether these changes are synuclein-dependent 
reversible, we generated tetracycline-suppressive (tet-off) conditional mice in which doxycycline (dox)-dependant expression of A30P alpha-synuclein is controlled by the CaMK/tTA promoter construct and can be regulated by administration of dox. The aim of this study was to test (i) whether alpha-synuclein expression is regulatable in this mouse model, (ii) whether A30P modulates olfactory neurogenesis and (iii) whether suppression of the A30P transgene restores levels of adult olfactory neurogenesis.

\section{Materials and methods}

\section{Tet-regulated mutant A30P alpha-synuclein-expressing mice}

The sequence encoding human A30P alpha-synuclein (Kruger et al., 1998) was amplified by PCR and cloned downstream of the tTAresponsive promoter of the pUHD 10-3 expression vector (Gossen \& Bujard, 1992) into the $X b a \mathrm{I}$ restriction site. Mice expressing the tTA construct under control of the calcium/calmodulin-dependent protein kinase II-alpha promoter line (designated CaMK in this study) have been previously described (Mayford et al., 1996).

For inducible expression of $\mathrm{A} 30 \mathrm{P}$ in transgenic mouse brain, heterozygous mice of the A30P line were crossed with the CaMK line (Fig. 1A). Lines were established by crossbreeding with C57Bl/6 (Charles River, Sulzfeld, Germany) and resulting offspring were analyzed by PCR of tail DNA using primers specific for the tTA sequence (for CaMK-expressing mice: tTA-F: 5'-GAC GAG CTC CAC TTA GAC GG-3'; tTA-R: 5'-TAC TCG TCA ATT CCA AGG GC-3') or the tet-responsive element (for alpha-synuclein A30P transgenics: pTRE-F: 5'-GAG ACG CCA TCC ACG CTG T-3'; pTRE-R: 5'-CAG TCT AGT TGT GGT TTG TCC A-3'), respectively. The number per group is stated individually for each experiment. The groups were balanced for sex.

In order to cease expression of the transgene, mice were treated with $2 \mathrm{mg} / \mathrm{mL}$ dox (Sigma-Aldrich, Munich, Germany) in a 5\% sucrose solution in the drinking water for 2 months (Fig. 1A). All experiments were carried out in accordance with the European Communities Council Directive of 24 November 1986 (86/609/EEC) and approved by the local governmental commission for animal health in Regensburg, Germany. All animals were 2 months of age at the beginning of the experiment.

\section{Antibodies and immunohistochemical analysis}

The following primary antibodies and final dilutions were used: mouse monoclonal anti-proliferating cell nuclear antigen (PCNA), 1 : 500 (Santa Cruz Biotechnology Inc., Santa Cruz, CA, USA); rat monoclonal anti-BrdU, 1:500 (Oxford Biotechnology, Oxford, UK); goat polyclonal anti-doublecortin (DCX) C18, 1 : 500 (Santa Cruz Biotechnology Inc., Santa Cruz, CA, USA); mouse monoclonal anti-neuronal nuclei $(\mathrm{NeuN}), 1: 500$; rabbit polyclonal antityrosine hydroxylase (TH), $1: 500$ (both from Chemicon, Temecula CA, USA); rabbit polyclonal anti-ubiquitin antibody, $1: 20$ (Dako enterprises, Hamburg, Germany); and rat monoclonal anti-human alpha-synuclein 15G7, 1: 10 (Axxora GmbH, Lörrach, Germany). The 15G7 IgG antibody is directed against human alpha-synuclein (116-131) peptide MPVDPDNEAYEMPSEE. This antibody has been described previously as detecting specifically human alpha-synuclein without crossreacting with endogenous murine alpha-synuclein (Kahle et al. 2000).

For immunohistochemistry, donkey antimouse, -rat, -rabbit or -goat biotinylated antibodies, 1:500 (Jackson Immuno Research, West Grove, PA, USA) were used as well as the avidin-biotin-peroxidase complex, 1 : 100 (Vectastain Elite, Vector Laboratories, Burlingame, CA, USA). Secondary antibodies for immunofluorescence were: donkey antirat and antigoat (FITC), $1: 500$; donkey antimouse and donkey antirabbit rhodamine, $1: 300$; donkey antirabbit, donkey antirat and donkey antimouse CY5, 1:500; and donkey antistreptavidin Texas red, 1: 500 (all from Jackson Immuno Research, West Grove, PA, USA).

\section{Western blot analysis}

For Western blot analyses of transcriptional control, two untreated and two dox-treated adult mice were killed with $\mathrm{CO}_{2}$ and tissues were frozen at $-80^{\circ} \mathrm{C}$. Total protein extracts were obtained as described previously (Nuber et al., 2008). Protein extracts $(20 \mu \mathrm{g}$ each) were fractionated on $17 \%$ SDS-PAGE and blotted on a nitrocellulose membrane (Whatman, Dassel, Germany). Immunoblots were blocked in 5\% dry milk in TBST buffer (Tris, $\mathrm{pH} 7.5$, $10 \mathrm{mM}$; $\mathrm{NaCl}, 0.15 \mathrm{~mm}$; and Tween $20,0.1 \%$ ) and subsequently probed with $15 \mathrm{G} 7$ alpha-synuclein antibody $(1: 5)$. Anti- $\beta$-actin (1 : 10.000; A4700; Sigma) was used as internal loading control. Bound antibodies were visualized with horseradish peroxidaseconjugated secondary antibodies and enhanced chemiluminescence (ECL or ECL ${ }^{\text {plus; }}$ GE Healthcare) and exposed to hyperfilm (GE Healthcare). IMAGEQUANT software 5.0 (GE Healthcare) was used to determine the optical density of protein bands and all data were normalized to the expression of $\beta$-actin.

\section{Experimental paradigm}

Mice of the CaMK line served as controls ('control'; $n=5$ ) for A30P transgenic mice ('A30P'; $n=5$ ). In an additional group, A30P expression was suppressed starting at the age of 2 months for 2 months via dox application in the drinking water ('A30P + dox'; $n=5$ ). To exclude effects of dox on examined neurogenic parameters, an additional group of control mice received dox for 2 months ('control + dox'; $n=4$; Fig. 1B). To mark newly generated cells, all groups received intraperitoneal injections of bromodeoxyuridine (BrdU; $50 \mathrm{mg} / \mathrm{kg}$ ) for five consecutive days at the age of 3 months and were killed 32 days after the first BrdU injection (paradigm; Fig. 1C). All mice were kept in a normal light-dark cycle (12 h light, $12 \mathrm{~h}$ dark) and had free access to food. The animals' water intake and weight were monitored daily. For histological processing, the animals were deeply anesthesized with a mixture of $10 \%$ ketamine (Ketanest ${ }^{\circledR}$; $25 \mathrm{mg} / \mathrm{mL}$ ), $1 \%$ acepromacine (Ventroquil ${ }^{\circledR} ; 0.25 \mathrm{mg} / \mathrm{mL}$ ) and $2 \%$ xylazine (Rompun ${ }^{\circledR} ; 1.25 \mathrm{mg} / \mathrm{mL}$ ) in $0.9 \% \mathrm{NaCl}$ solution, and perfused transcardially with $4 \%$ paraformaldehyde (PFA) in $100 \mathrm{~mm}$ phosphate buffer (PB), pH 7.4. After removal, the brains were postfixed in 4\% PFA in $100 \mathrm{~mm}$ PB for $24 \mathrm{~h}$ and placed in a solution of $30 \%$ sucrose in PB. Brains were cut saggitally into $25-\mu \mathrm{m}$ sections using a sliding microtome (Leica, Bensheim, Germany) on dry ice. The brains were then stored in cryoprotectant (ethylene glycol, glycerol and $\mathrm{PB}, \mathrm{pH} 7.4,1: 1: 2$ by volume) at $-20^{\circ} \mathrm{C}$ until further processing.

\section{Gallyas technique}

Brains of an adult A30P, wild-type control and a dox-treated mouse $(\mathrm{A} 30 \mathrm{P}+$ dox $)$ were fixed in formalin and embedded in paraffin. Seven-micrometer sections with extensive alpha-synuclein expression (OB, substantia nigra and nucleus accumbens) were examined for their argyrophilia with Gallyas silver staining (Gallyas, 1971). 
A

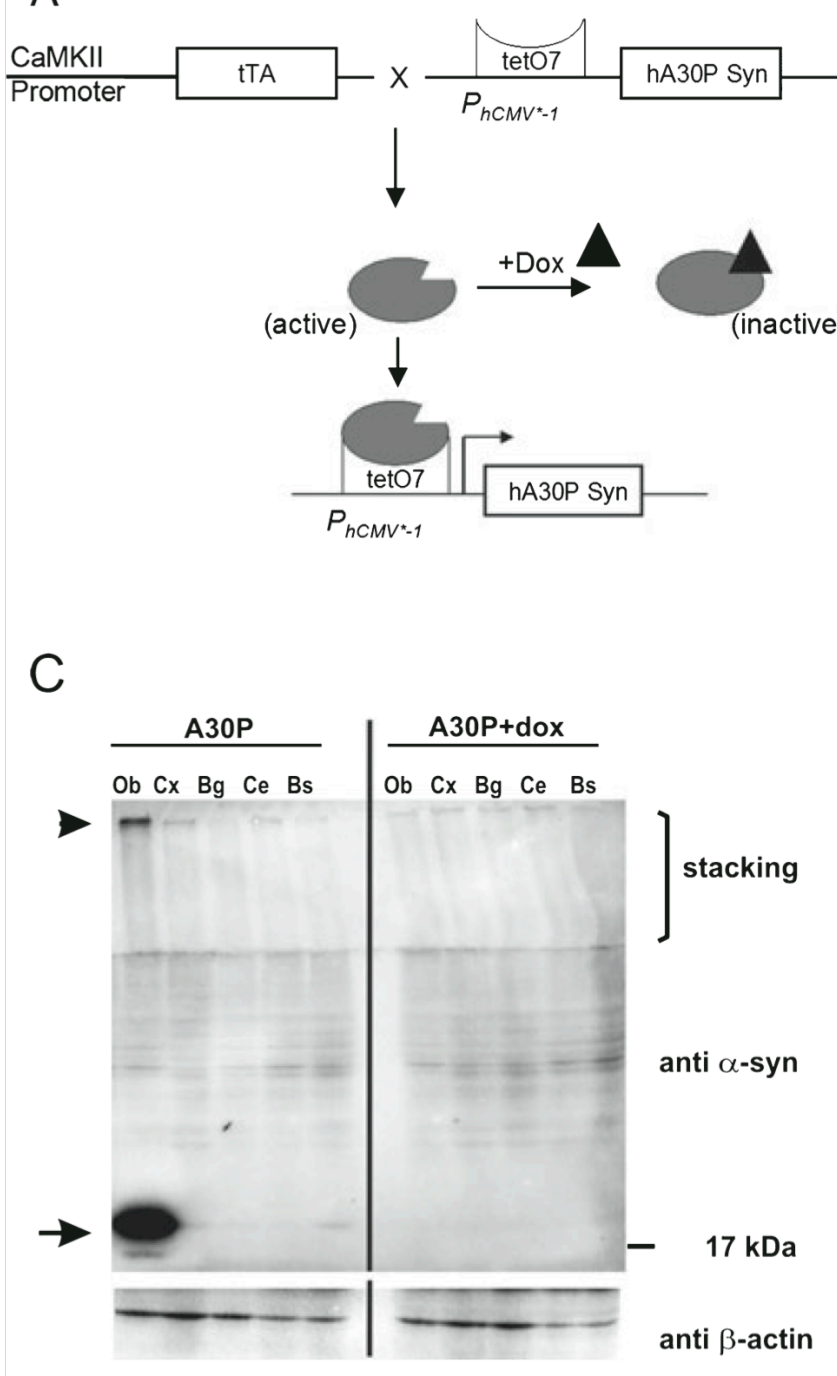

B

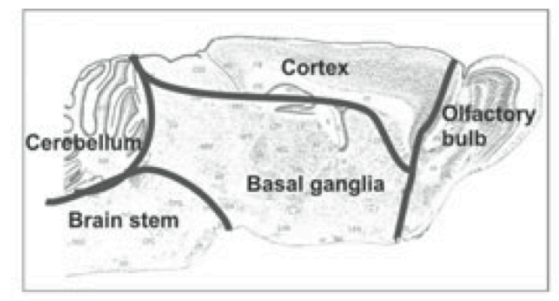

D
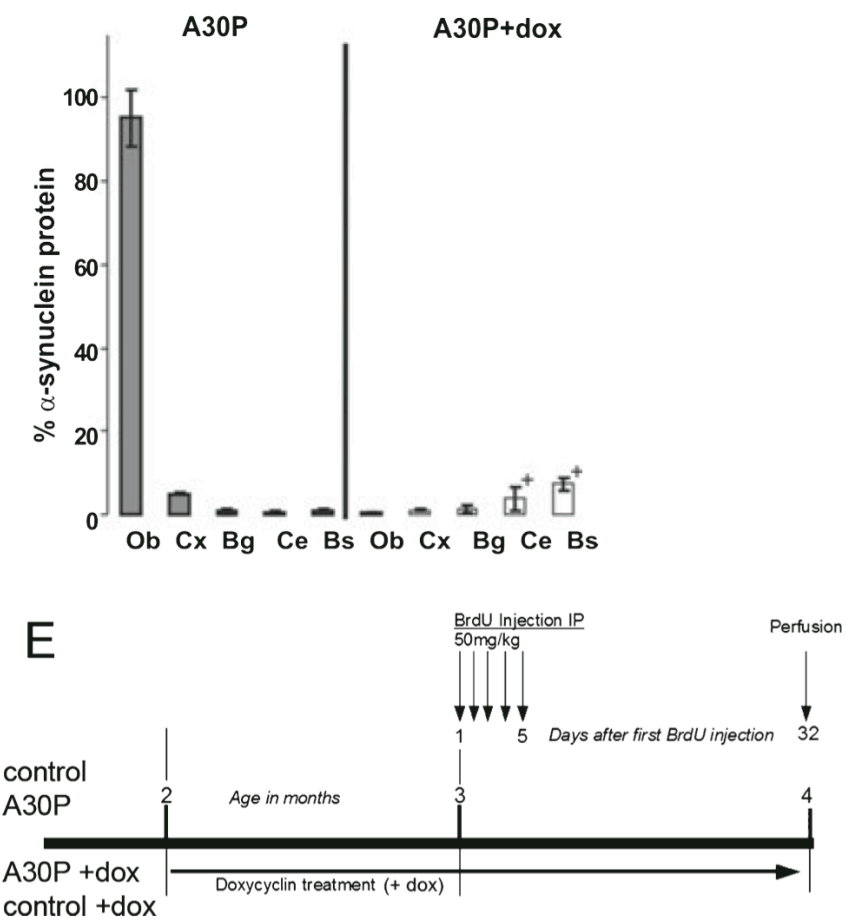

FIG. 1. Experimental design. (A) Tetracycline-controlled transactivator (tTA) expression was driven by the CaMK promoter. In its active form tTa binds to the tetO7 sequence of the minimal promoter $\left(\mathrm{P}_{\mathrm{hCMV} *-1}\right)$ and initiates expression of the A30P transgene, localized downstream. Expression can be inhibited by dox as it binds to tTA, making it inactive. (B) For Western blot analysis (WBA), subregional dissection areas of mice brain were determined according to the stereotaxic atlas of Paxinos \& Franklin (2001). (C) WBA (30 $\mu \mathrm{g}$ per lane) of human alpha-synuclein in a dissected A30P mouse brain homogenate using the 15G7-alpha-synucleinantibody and $\beta$-actin as internal control. The strong signal of $\sim 19 \mathrm{kDa}$ corresponds to monomeric alpha-synuclein (arrow). The high molecular signal in the stacking gel might present aggregated forms of alpha-synuclein (arrowhead). Administration of doxycycline for 8 weeks (A30P + dox) reduced alpha-synuclein expression to basal levels in adult mice. (D) The $19 \mathrm{kDa}$ signal intensities were quantified using IMAGEQUANT software and normalized to $\beta$-actin staining in the same line to correct for loading differences. After normalization the amount of alpha-synuclein was calculated as a percentage. (E) Experimental design and injection paradigm. All four experimental groups (control, A30P, A30P + dox and control + dox) received daily BrdU injections for 5 days at age 3 months, 32 days prior to perfusion. The control + dox and A30P + dox groups received dox in their drinking water to stop A30P expression for 2 months while the control and the A30P group did not receive dox; +, nonspecific background staining of membrane. OB, olfactory bulb; $\mathrm{Cx}$, cortex; Bg, basal ganglia; Ce, cerebellum; Bs, brain stem.

\section{Immunohistochemistry}

Free-floating sections were treated with $0.6 \% \mathrm{H}_{2} \mathrm{O}_{2}$ in Tris-buffered saline (TBS; $\mathrm{NaCl}, 0.15 \mathrm{M}$; and Tris- $\mathrm{HCl}, \mathrm{pH} 7.5,0.1 \mathrm{M}$ ) for $30 \mathrm{~min}$ to stop endogenous peroxidase activity, and afterwards incubated in TBS with $0.25 \%$ Triton-X100 and 3\% normal donkey serum (dkS) for $30 \mathrm{~min}$. Incubation with primary antibodies was performed in $3 \% \mathrm{dkS}$ at $4^{\circ} \mathrm{C}$ overnight. The sections were then incubated with secondary antibodies for $1 \mathrm{~h}$ and afterwards rinsed in TBS. Avidin-biotinperoxidase complex was applied for $1 \mathrm{~h}$ and then peroxidase detection was performed using $25 \mathrm{mg} / \mathrm{mL}$ DAB, $0.01 \% \mathrm{H}_{2} \mathrm{O}_{2}$ and $0.04 \% \mathrm{NiCl}_{2}$ in TBS for $10 \mathrm{~min}$. After the sections were mounted on gelatine-coated glass slides, they were put in NeoClear ${ }^{\circledR}$ and coverslipped with
NeoMount ${ }^{\circledR}$ (both from Merck, Darmstadt, Germany). To increase the immunoreactivity for ubiquitin, mounted sections were boiled in a $10 \mathrm{~mm}$ citrate buffer for $15 \mathrm{~min}$ before further immunohistochemical processing. To detect BrdU-labeled nuclei, DNA denaturation steps were performed prior to immunohistochemistry or immunofluorescence procedures. Therefore, sections were incubated for $2 \mathrm{~h}$ in $50 \%$ formamide with $2 \times \mathrm{SSC}(2 \times \mathrm{SSC}$ : $0.3 \mathrm{M} \mathrm{NaCl}$ with $0.03 \mathrm{M}$ sodium citrate) at $65^{\circ} \mathrm{C}$ and afterwards rinsed three times for $5 \mathrm{~min}$ in TBS. Finally, the sections were incubated in $2 \mathrm{M} \mathrm{HCl}$ at $37^{\circ} \mathrm{C}$ and rinsed in $0.1 \mathrm{M}$ boric acid ( $\mathrm{pH} 8.5$ ) for $10 \mathrm{~min}$. The specificity of the immunohistochemical labeling was determined by both a negative control, replacing the primary antibody with serum, and a positive control using 
the antibody with tissue of a transgenic alpha-synuclein wild-type mouse (Nuber et al., 2008)

\section{Immunofluorescence}

Untreated or BrdU-pretreated free-floating sections were washed in TBS and incubated in $3 \% \mathrm{dkS}$ for $2 \mathrm{~h}$. Afterwards, a combination of antibodies for triple labeling (rat anti-synuclein, goat anti-DCX, rabbit anti-TH, rat anti-BrdU or mouse anti-NeuN) was applied in $3 \% \mathrm{dkS}$ for $48 \mathrm{~h}$ at $4^{\circ} \mathrm{C}$. To enhance the fluorescence signal for alpha-synuclein, sections were treated with a biotinylated donkey antirat antibody for $2 \mathrm{~h}$ in $3 \% \mathrm{dkS}$, washed and finally incubated with immunoflurescent antibodies (donkey anti-streptavidin Texas red, donkey antigoat FITC, donkey antirabbit $\mathrm{Cy} 5$ ) in $3 \% \mathrm{dkS}$ for $2 \mathrm{~h}$ in darkness. After several washes in TBS, sections were mounted on glass slides and coverslipped using Prolong (Molecular Probes, Eugene, USA). In case of alphasynuclein-TH-BrdU triple immunofluorescence, alpha-synuclein-TH stainings were performed, afterwards postfixed in 4\% PFA and then pretreated and stained for BrdU in darkness.

\section{Terminal deoxynucleotidyl transferase dUTP nick-end labeling (TUNEL)}

Histological detection of TUNEL-positive cells undergoing programmed cell death (Gavrieli et al., 1992) was performed using the Apoptag In Situ Cell Death Detection Kit (Intergene, Purchase, NY, USA) in a modified procedure for free-floating sections as previously described (Biebl et al., 2005).

\section{Counting procedures}

For quantification a systematic unified random counting procedure, similar to the optical dissector (Gundersen et al., 1988), was used with a semi-automatic stereology system (Stereoinvestigator, MicroBrightField, Colchester, VT, USA) as described previously (Winner et al., 2007), using Leica objectives (Leica TCS-NT, Bensheim, Germany; PL APO $20 \times / 0.6$ and PL APO $40 \times / 1.25-0.75$ ). Every sixth section was analysed. PCNA-positive cells in the SVZ were counted randomly within a $20 \times 20 \mu \mathrm{m}$ counting frame, which was spaced in a $100 \times 100 \mu \mathrm{m}$ counting grid. In the OB granule cell layer BrdUand DCX-positive cells within a $40 \times 40 \mu \mathrm{m}$ counting frame, which was spaced in a $300 \times 400 \mu \mathrm{m}$ counting grid, were analyzed. In the glomerular layer, newly generated cells are less frequent and TUNELpositive cells are comparatively rare in the $\mathrm{OB}$. Therefore, no counting frames were used in those cases but the region was exhaustively counted on each section. On average, 100 BrdU-positive cells were analyzed in the granule cell and glomerular layers of the $\mathrm{OB}$ for neuronal differentiation by using 400 -fold magnification on a confocal scanning laser microscope (Leica TCS-NT), equipped with a Leica objective (PL APO 40×/0.75). Newborn cells (BrdU-positive) were determined for coexpression of neuronal (BrdU-NeuN) markers in the granule cell layer and dopaminergic and neuronal (BrdU-NeuN-TH) markers in the glomerular layer. In addition, coexpression for alphasynuclein and BrdU was analyzed in both regions. The numbers of the confocal planes are indicated in the figure legends.

\section{Statistical analysis}

The data are expressed as mean values $\pm \mathrm{SD}$. Statistical analysis was performed using a one-way ANOVA followed by Tukey's multiple comparison test (PRISM; Graph Pad Software, CA, USA) for comparison of experimental groups.

\section{Results \\ Human alpha-synuclein expression in conditional A30P transgenic mice}

For conditional expression of human A30P alpha-synuclein in transgenic mouse brain, mice of the A30P line were crossed with the CaMK line to get double-transgenic offspring (designated A30P mice) in which expression should be regulatable by administration of dox (Fig. 1A). The A30P alpha-synuclein expression pattern and the regulation of transgene expression were analyzed by Western blot (Fig. 1) and immunohistochemistry (Figs 3 and 4). Western blot analysis of different brain regions (Fig. 1B and C) detected strong alpha-synuclein signals in the $\mathrm{OB}$ and relatively weak signals in cortex, basal ganglia and brain stem. The OB protein extract also revealed an immunopositive signal in the stacking gel, implying the presence of aggregated A30P alpha-synuclein formations, which were not seen in the other brain regions or the untreated and dox-treated mice. Expression was decreased by $>90 \%$ after treatment with dox (A30P + dox; Fig. 1D) and therefore is tightly regulatable in adult A30P mice. Silver staining, which is known to detect intraneuronal cytoplasmic inclusions reminiscent of Lewy bodies in an alphasynuclein tg mouse model (Neumann et al., 2002) revealed pathological alterations in areas with extensive A30P expression, i.e. OB (Fig. 2B) and substantia nigra (Fig. 2D). These argyrophilic profiles were not seen in silver-stained sections of the control mouse (Fig. 2A) and a dox-treated A30P mouse (Fig. 2C), the latter indicating lack of the observed pathology after dox treatment (Table 1).

Immunohistochemically, human alpha-synuclein was present in the $\mathrm{OB}$, the olfactorial tubercle, the nucleus accumbens, the medial forebrain bundle, the striatum including the ventral pallidum and the substantia nigra (Fig. 3A) in A30P mice. The 15G7 antibody did not show any human alpha-synuclein immunoreactivity in the SVZ, the RMS or the hippocampus (Fig. 3A). In the OB of A30P mice, human alpha-synuclein was present in the granule cell and plexiform layer as

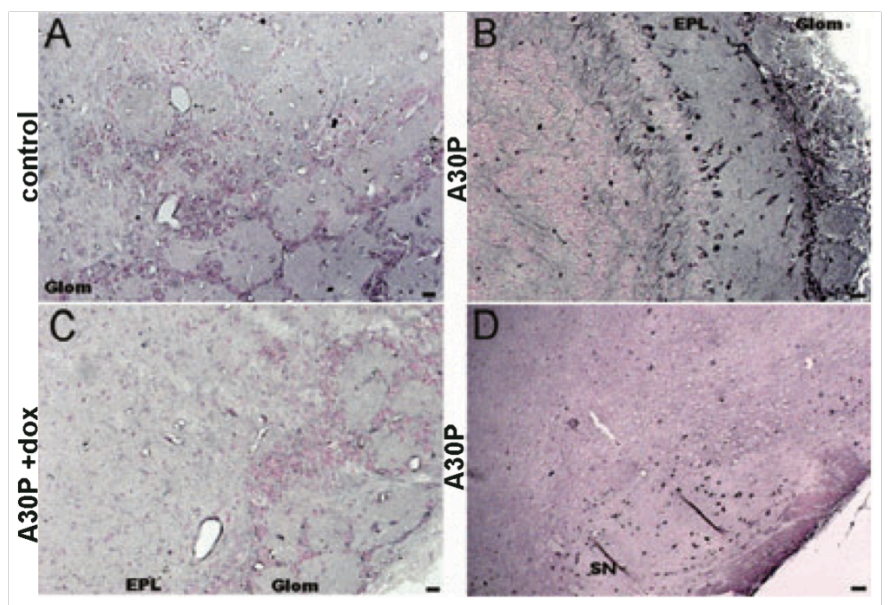

FIG. 2. Pathology of a A30P mouse brain. Gallyas silver stain revealed argyrophilic dystrophic neurites and cell bodies in the glomerular (Glom) and external plexiform layer (EPL) in (B) A30P mouse brain which were not seen in (A) control or in (C) dox-treated mouse brain. (D) Pathological cells were also observed in the substantia nigra in A30P mouse brain. Scale bars, $20 \mu \mathrm{m}$ $(\mathrm{A}-\mathrm{C}), 50 \mu \mathrm{m}$ (D). 
TABLE 1. Summary of results from the four experimental groups

\begin{tabular}{|c|c|c|c|c|}
\hline & $\begin{array}{l}\text { Control } \\
(n=5)\end{array}$ & $\mathrm{A} 30 \mathrm{P}(n=5)$ & $\begin{array}{l}\text { A } 30 \mathrm{P}+\mathrm{dox} \\
(n=5)\end{array}$ & $\begin{array}{l}\text { Control }+ \text { dox } \\
(n=4)\end{array}$ \\
\hline $\begin{array}{l}\text { (A) Proliferation in the SVZ } \\
\text { PCNA }\left(\times 10^{2}\right)\end{array}$ & $14.0 \pm 3.2$ & $13.0 \pm 4.1$ & $12.3 \pm 2.3$ & $10.4 \pm 1.9$ \\
\hline $\begin{array}{l}\text { (B) Neurogenesis in the OB } \\
\text { BrdU }\left(\times 10^{3}\right) \\
\% \text { NeuN } \\
\text { BrdU } \times \% \text { NeuN }\left(\times 10^{3}\right) \\
\% \text { Alpha-synuclein } \\
\text { DCX }\left(\times 10^{3}\right)\end{array}$ & $\begin{array}{l}\text { rer } \\
43.1 \pm 3.7 \\
85 \pm 7 \\
36.8 \pm 3.2 \\
0 \\
187.6 \pm 52.8\end{array}$ & $\begin{aligned} 29.7 & \pm 3.7^{\mathrm{F} \# \#,++} \\
86 & \pm 7 \\
26.0 & \pm 3.3^{\# \#} \\
4.4 & \pm 2.5 \\
177.4 & \pm 30.0\end{aligned}$ & $\begin{aligned} 39.6 & \pm 5.1^{* * * *} \\
87 & \pm 3 \\
34.4 & \pm 4.5^{+} \\
0 & \\
180.6 & \pm 19.8\end{aligned}$ & $\begin{array}{c}42.4 \pm 2.5 \\
83 \pm 5 \\
35.1 \pm 2.1 \\
0 \\
164.3 \pm 18.1\end{array}$ \\
\hline $\begin{array}{l}\text { (C) Neurogenesis in the OB } \\
\text { BrdU }\left(\times 10^{2}\right) \\
\text { BrdU } \times \% \text { NeuN }\left(\times 10^{2}\right) \\
\text { BrdU } \times \% \mathrm{TH} \\
\text { \%NeuN } \\
\text { \% TH } \\
\text { \%Alpha-synuclein }\end{array}$ & $\begin{array}{l}14.8 \pm 4.1 \\
11.0 \pm 3.1 \\
302 \pm 84 \\
76 \pm 10 \\
20 \pm 7 \\
0\end{array}$ & $\begin{aligned} 8.8 & \pm 1.2^{\# \#+1,++} \\
7.3 & \pm 1.0 \\
179 & \pm 27^{\# \#+,++} \\
83 & \pm 10 \\
23 & \pm 10 \\
69 & \pm 10\end{aligned}$ & $\begin{aligned} 14.2 & \pm 2.9^{* * *} \\
12.2 & \pm 2.5^{* * *} \\
296 & \pm 44^{* * *} \\
86 & \pm 8 \\
21 & \pm 7 \\
0 & \end{aligned}$ & $\begin{aligned} 14.2 & \pm 2.3 \\
11.2 & \pm 1.8 \\
391 & \pm 62 \\
79 & \pm 4 \\
28 & \pm 6 \\
0 & \end{aligned}$ \\
\hline $\begin{array}{l}\text { (D) Apoptotic cells in the O } \\
\text { Granule cell layer } \\
\text { Glomerular layer }\end{array}$ & $\begin{array}{l}245 \pm 55 \\
162 \pm 43\end{array}$ & $\begin{array}{l}484 \pm 127^{\# \#,+} \\
334 \pm 122^{\#}\end{array}$ & $\begin{array}{l}263 \pm 52^{* *} \\
187 \pm 47^{*}\end{array}$ & $\begin{array}{l}287 \pm 41 \\
231 \pm 48\end{array}$ \\
\hline
\end{tabular}

All data (numbers and percentages) are given \pm SD. (A) The numbers of PCNA-positive cells are presented for the SVZ. (B) Quantification of neurogenesis in the granule cell layer is shown by the number of newly generated BrdU-positive cells, the percentages of NeuN- and alpha-synuclein-positive cells and the calculated number of new neurons $(\mathrm{BrdU} \times \% \mathrm{NeuN})$. In addition, DCX total cell numbers are given. No significant differences in proliferation were found between the four groups. ${ }^{\#} P<0.01$ and ${ }^{\# \# \#} P<0.001$ compared to control; ${ }^{+} P<0.01$ and ${ }^{++} P<0.001$ compared to control + dox; ${ }^{* * *} P<0.001$ compared to A30P. (C) Neurogenesis in the glomerular layer is reflected by BrdU-positive cells, and percentages of BrdU-positive cells expressing NeuN (\%NeuN) and TH (\%TH) as well as the calculated total numbers of new neurons $(\mathrm{BrdU} \times \% \mathrm{NeuN})$ and total calculated numbers of dopaminergic neurons $(\mathrm{BrdU} \times \% \mathrm{TH}) . \# \# P 0.001 \mathrm{compared}$ to control; ${ }^{++} P<0.001$ compared to control + dox; ${ }^{* *} P<0.001$ compared to A30P. (D) Cell death in the granule cell and glomerular layers measured by TUNELpositive profiles. ${ }^{\#} P<0.05$ and ${ }^{\# \#} P<0.01$ compared to control; ${ }^{+} P<0.01$ compared to control + dox; ${ }^{*} P<0.05$ and $* * *<0.01$ compared to A30P.

well as in the glomeruli (Fig. 3D). Immunoreactivity in A30P animals was strongest in the glomerular cell layer, showing cells with a global diffuse cellular alpha-synuclein staining pattern and a prominent immunoreactivity in the processes (Fig. $3 \mathrm{G}$ and N). In the external plexiform layer, immunopositive signals were observed within neurites; some of them presented with pathological round dendritic swellings and pearlstring-like sections (Fig. 3G and O). In the granule cell layer of $\mathrm{A} 30 \mathrm{P}$ mice, immunoreactivity was detected in the soma and processes of neurons (Fig. 3P). As cytoplasmatic ubiquitin inclusions are another key feature of PD and other alpha-synucleinopathies (Gibb \& Lees, 1988; Spillantini et al., 1997), and ubiquitin immunoreactivity is used as an additional marker in alpha-synucleinopathies (Gai et al., 1995; Braak et al., 1999) in humans and in animal models (Valente et al., 2004; Shults et al., 2005), we analyzed A30P mice for ubiquitin-positive structures in the $\mathrm{OB}$. Immunoreactivity for ubiquitin was found in the cytoplasm of granule and glomerular cells in A30P animals (Fig. 3H and L).

In the treated $\mathrm{A} 30 \mathrm{P}+$ dox group, immunohistochemically rare alphasynuclein signal was detected in the alpha-synuclein-positive regions of the untreated A30P group (Fig. 3B). In particular, after 2 months of dox treatment transgenic alpha-synuclein was strongly reduced in every region of the $\mathrm{OB}$ (Fig. 3C, E and I), paralleled by faint staining for ubiquitin compared to untreated A30P animals (Fig. 3F and J). These results show that the expression of the transgene was sufficiently suppressed by dox in adult A30P mice after 2 months. Using the humanspecific 15G7 antibody, no alpha-synuclein staining was found in the control group or in dox-treated controls (data not shown).

\section{Colabeling with neuroblast and neuronal markers in the $O B$}

To determine cell type-specific expression of human alpha-synuclein in the OB, RMS and SVZ, coexpression studies of human alpha- synuclein with the neuroblast marker DCX, the newly generated cell marker BrdU or the dopamine-expressing-cell marker TH were performed. Stainings in which the primary antibody was omitted resulted in absence of immunoreactivity in those brain sections whilst staining in transgenic alpha-synuclein wild-type mice led to a similar staining pattern (data not shown)

We detected no coexpression of alpha-synuclein and DCX in the SVZ or RMS of A30P animals. Rare DCX/alpha-synuclein doublepositive neuronal progenitors were found in the granule cell layer (Fig. 4A-C). Dopaminergic neurons of the glomerular layer frequently colabeled with alpha-synuclein. Some of the alpha-synuclein/ TH-coexpressing cells were BrdU-positive, indicating the presence of newly generated dopaminergic neurons (Fig. 4E-H). A quantitative analysis of colabeling of alpha-synuclein with newly generated neurons showed $4 \%$ of BrdU-positive cells colabeled with alphasynuclein in the granule cell layer, whereas $69 \%$ of BrdU-positive cells colabeled with alpha-synuclein in the glomerular layer.

\section{Proliferation was not affected in A30P-expressing mice}

Proliferation in the SVZ was assessed by quantification of PCNApositive cells. Unchanged numbers of proliferating cells in A30P animals compared to the control group revealed no significant difference in proliferation in the SVZ $(P>0.05$; Table 1A).

\section{Decreased olfactory neurogenesis of A30P mutant mice}

To measure the level of $\mathrm{OB}$ neurogenesis, we stereologically analyzed BrdU cell numbers in the granule cell layer and the glomerular cell layer separately (Table 1B and C). In addition, the neuronal identity of the newly generated cells was characterized by colabeling BrdU with NeuN and TH. The total number of newly generated 

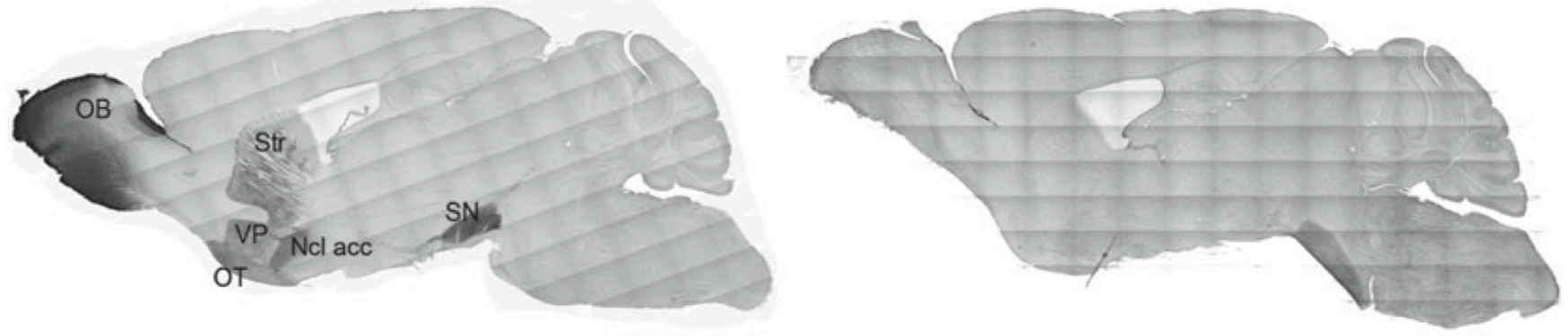

A

B

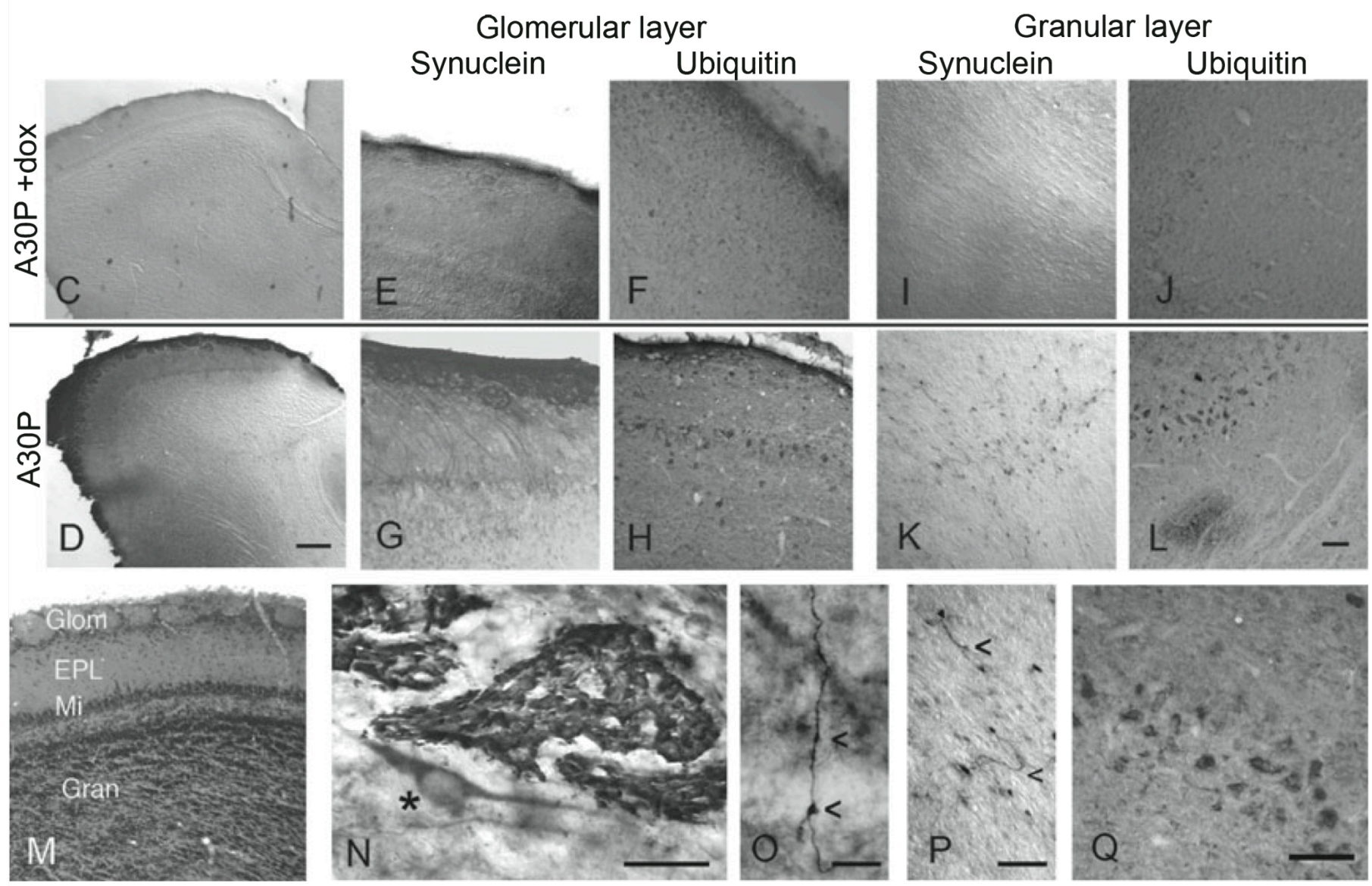

FIG. 3. Alpha-synuclein and ubiquitin immunoreactivity in A30P and A30P + dox animals. (A) Saggital overview of an A30P mouse brain with alphasynuclein expression in the substantia nigra $(\mathrm{SN})$, the nucleus accumbens $(\mathrm{Ncl}$ acc), the striatum (Str), the ventral pallidum (VP), the olfactorial tubercle (OT) and the OB. (B) No alpha-synuclein expression was observed in A30P + dox animals. (M) Anatomical overview of the OB layers as revealed by Nissl staining: glomerular layer (Glom), external plexiform layer (EPL), mitral layer (Mi) and granule cell layer (Gran). (D, G and K) Higher magnifications of the OB alphasynuclein expression in A30P mice. (C, E and I) No alpha-synuclein expression was present in the OB of A30P + dox animals. (F, H, J and L) Ubiquitinylation in $(\mathrm{H})$ the Glom and $(\mathrm{L})$ the Gran in A30P mice compared to (F and J, respectively) A30P + dox. (N) The Glom of A30P animals revealed a diffuse cellular alpha-synuclein expression of glomerular cells $\left(^{*}\right)$ as well as a dendritic staining pattern in the glomeruli. (O) Example of a Lewy-like neurites in the external plexiform layer (arrowheads) and pearlstring-like sections. (P) Alpha-synuclein in the cell bodies and processes (arrowheads) of granule cell cells. (Q) Granule cells stained for ubiquitin showed a cellular staining pattern. Scale bars: $250 \mu \mathrm{m}$ (in D for C and D), $50 \mu \mathrm{m}$ (in L, for E-L), $50 \mu \mathrm{m}(\mathrm{N}$ and Q), $10 \mu \mathrm{m}(\mathrm{O})$ and $25 \mu \mathrm{m}(\mathrm{P})$.

BrdU/NeuN-coexpressing cells (new neurons) or BrdU/NeuN/THcoexpressing cells (new dopaminergic neurons) was used to evaluate modulation of neurogenesis.
In the granule cell layer we observed a $41 \%$ reduction in BrdUpositive nuclei in the $\mathrm{A} 30 \mathrm{P}$ mice compared to the control group $(P<0.001$; Fig. 5A and B). Analysis of the amount of neuronal 

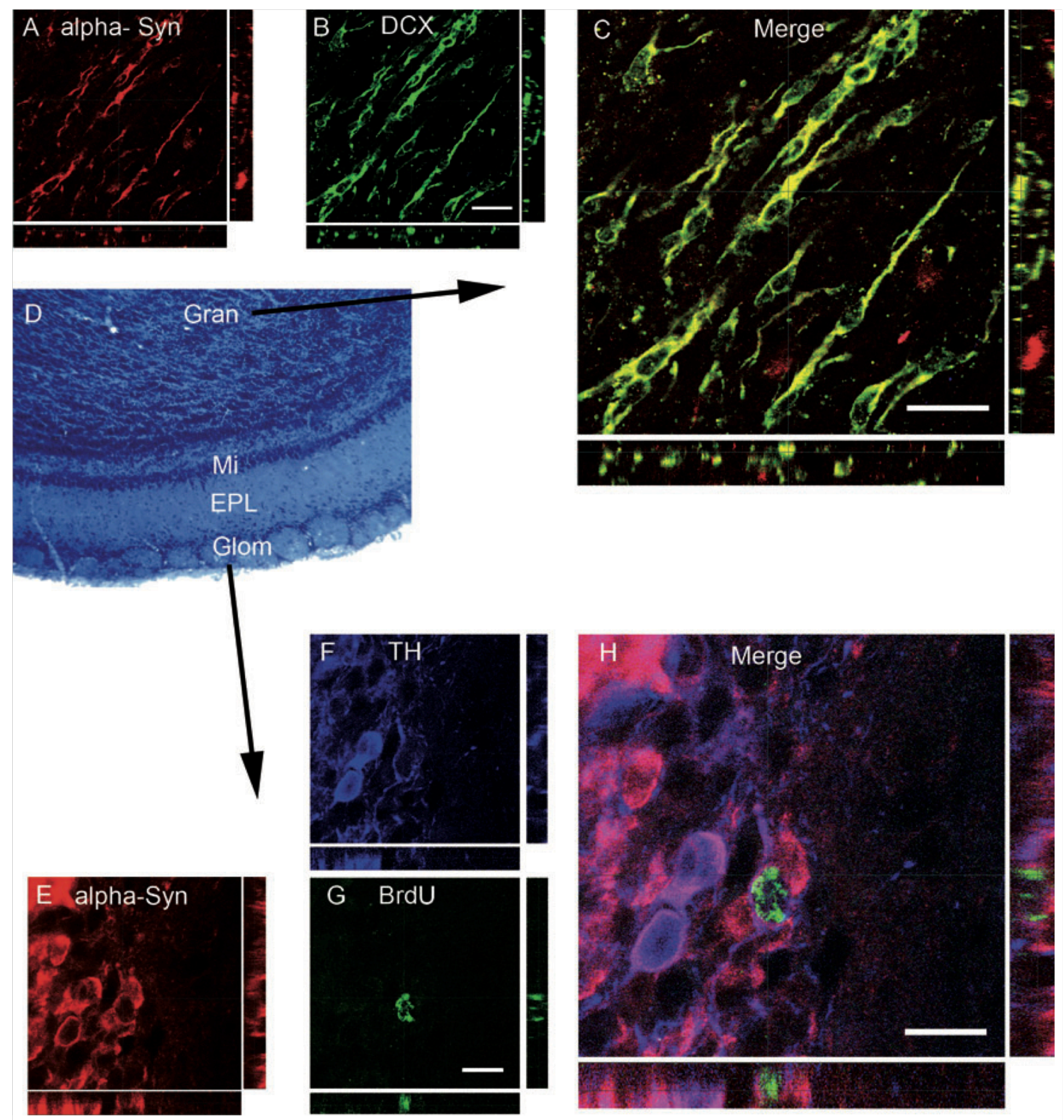

FIG. 4. Alpha-synuclein accumulation in glomerular dopaminergic neurons. (D) The anatomical layers of the OB are shown in a Nissl-stained section; Glom, glomerular layer; EPL, external plexiform layer, Mi, mitral layer; and Gran, granule cell layer. Confocal analysis of alpha-synuclein expression in (A-C) the Gran and (E-H) the Glom of the OB revealed (C, Merge) a colocalization of alpha-synuclein (A; alpha Syn) in doublecortin (B; DCX)-positive neuroblasts. In the Glom, (E) alpha-Syn expression was found in (G) newly generated BrdU-positive cells that adopt a dopaminergic phenotype, (H) shown via TH colabeling. Colabeling was analyzed sequentially at each wavelength and in the $z$-axis using 30 confocal planes for the analysis of (A-C) DCX/alpha-synuclein colabeling and for (E-H) the analysis of BrdU/alpha-synuclein colabeling. Scale bars, $20 \mu \mathrm{m}(\mathrm{A}-\mathrm{C}), 10 \mu \mathrm{m}(\mathrm{E}-\mathrm{H})$.

differentiation in the granule cell layer revealed no significant difference between the control and the A30P groups $(P>0.05,85 \%$ and $86 \%$ neuronal differentiation; Table 1B, Fig. 5G-I). Multiplica- tion of newly generated cells and neuronal differentiation resulted in a decrease in BrdU/NeuN cell numbers by $25 \%(P<0.001$; Fig. 5E). 

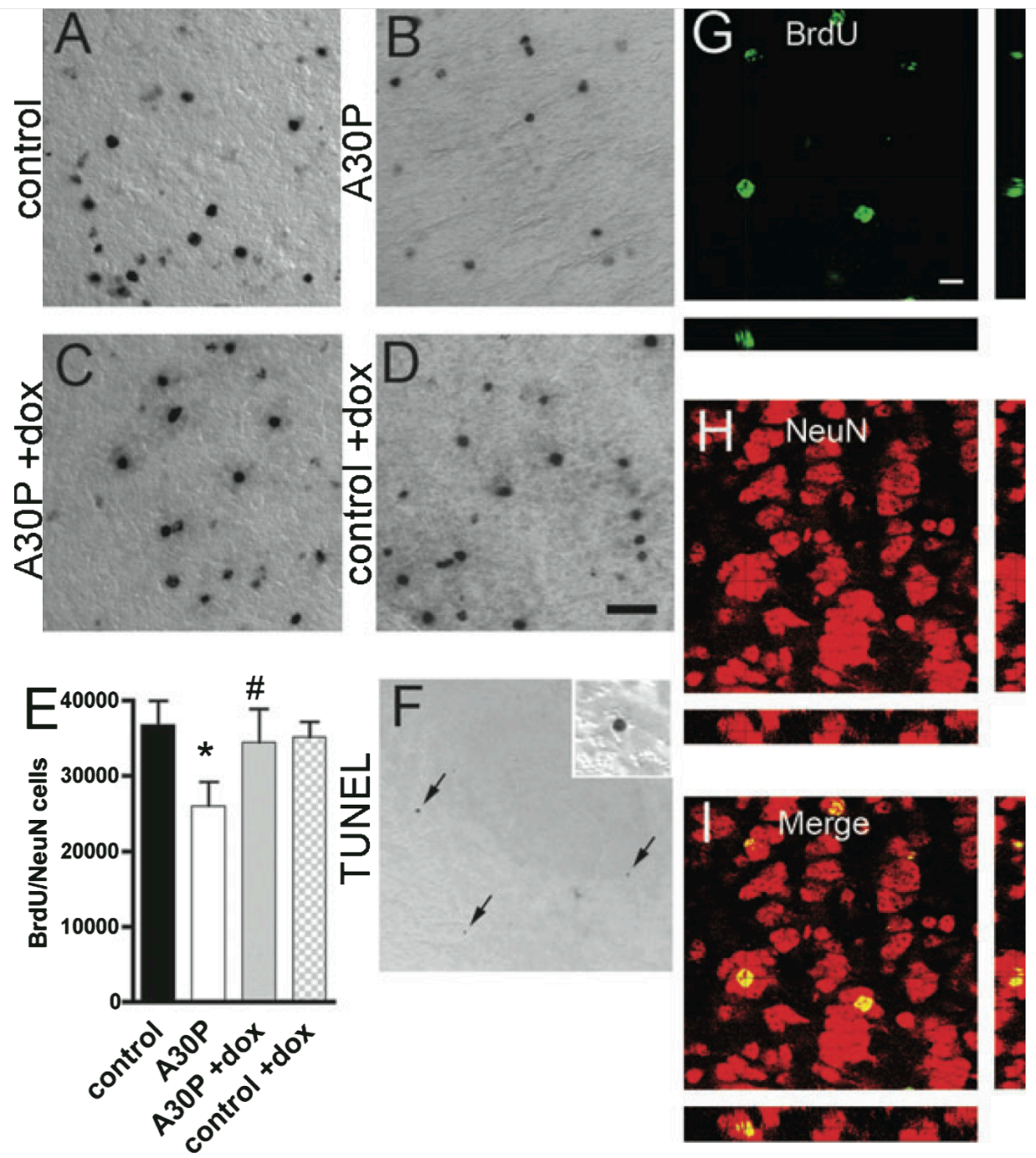

FIG. 5. Neurogenesis in the granule cell layer. Quantification of the total number of newly generated cells in the granule cell llayer of (A) control, (B) control + dox, (C) A30P and (D) A30P + dox animals revealed a decrease in newly generated cells in A30P animals compared to controls which was not observed after transgene suppression in $\mathrm{A} 30 \mathrm{P}+$ dox animals. Thus (E) a decrease in neurogenesis (expressed by BrdU/NeuN\% cell numbers) in A30P animals was seen, accompanied by (F) an increase in TUNEL-positive profiles. (G-I) Confocal microscopy revealing (I; merge) colocalization of (G; BrdU, green) BrdU with (H; NeuN, red) NeuN. Colabelling was analysed sequentially at each wavelength and in the $z$-axis using 30 confocal planes. Error bars in E represent $\mathrm{SD}$; ${ }^{*} P<0.001$ compared to control; ${ }^{\#} P<0.001$ compared to A30P. Scale bars, $25 \mu \mathrm{m}$ (A-D and G-I).

\section{Dopaminergic differentiation in the glomerular cell layer was decreased in A30P mutant mice}

In the glomerular layer a $40 \%$ reduction in BrdU-positive nuclei was present in the $\mathrm{A} 30 \mathrm{P}$ group compared to the control group $(P<0.01$; Fig. 6A and B, Table 1C). Newly generated dopaminergic neurons $(P<0.01$; Fig. $7 \mathrm{~F})$ were significantly reduced in the A30P group compared to the control group. These data imply that dopaminergic neurogenesis was decreased in A30P animals. Although there was a $34 \%$ decrease in BrdU/NeuN-positive new cells in the OB glomerular layer, these results did not reach significant levels $(P>0.05)$. Thus TH-positive cells were preferentially affected, as indicated by a larger decrease in newly generated dopaminergic neurons (Table 1C, Fig. 7E).

\section{Analysis of neurogenesis in A30P + dox animals}

Subsequently, we analysed neurogenesis in A30P + dox animals. A30P mice received dox to stop transgene expression starting at the age of
2 months (for paradigm see Fig. 1E). Proliferation was not significantly different in this group compared to the A30P group (Table 1A).

The total number of newly generated granule cells in the $\mathrm{A} 30 \mathrm{P}+\mathrm{dox}$ group was significantly increased compared to the A30P group (33\% increase, $P<0.01)$ but the percentage of neuronal differentiation was not. This resulted in a significantly increased neurogenesis in the $\mathrm{A} 30 \mathrm{P}+$ dox group compared to the A30P group ( $40 \%$ increase, $P<0.001$; Fig. $5 \mathrm{~B}, \mathrm{C}$ and $\mathrm{E}$ ). The total number of new neurons in the $\mathrm{A} 30 \mathrm{P}+$ dox group was similar to that in the control group ( $P>0.05$; Table 1B, Fig. 5A, D and E).

In the glomerular cell layer of A30P + dox animals the total number of BrdU-positive cells was significantly increased compared to the A30P group $(P<0.05$; Table $1 \mathrm{C}$, Fig. 6A, C and E). Eighty-six per cent of the newly generated cells of the A30P + dox group differentiated into neurons and $21 \%$ adopted a dopaminergic phenotype. This resulted in increased levels of dopaminergic and overall neurogenesis $(P<0.001$; Fig. $7 \mathrm{~F})$ compared to the A30P group (Table 1C). To exclude any effect of the 2 -month dox treatment on proliferation and 


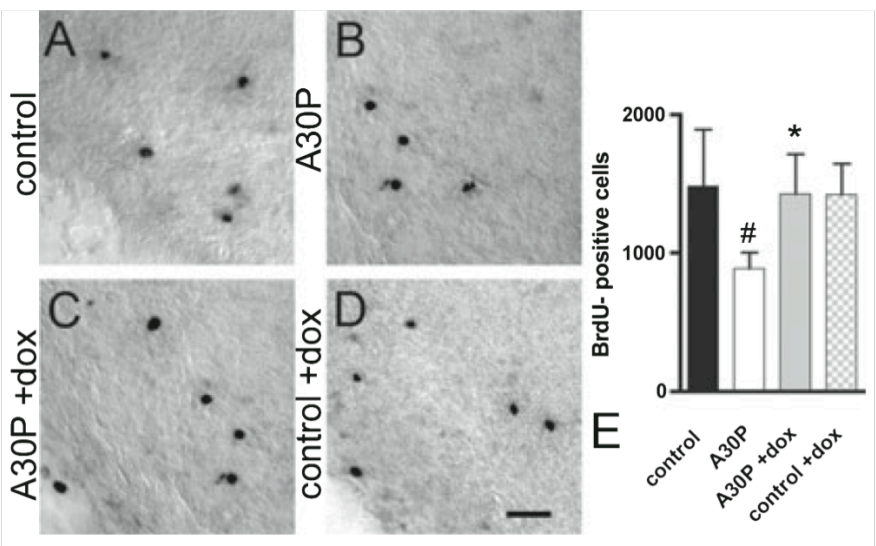

FIG. 6. Newly generated cells in the glomerular cell layer. Reduction in newly generated cells in the glomerular cell layer was found in (B) the A30P group compared to (A) control and (D) control + dox groups. (C) Blocking transgene expression in $A 30 P+$ dox animals resulted in an increase in the number of newly generated cells compared to A30P animals, similar to (E) control groups. Error bars are SD; ${ }^{*} P<0.001$ compared to control; ${ }^{\#} P<0.001$ compared to control + dox. Scale bars, $25 \mu \mathrm{m}(\mathrm{A}-\mathrm{D})$.

neuronal differentiation, control animals that received dox for 2 months were quantified. No change in proliferation was found in the control + dox group compared to the control group. These results indicate that dox had no influence on neurogenesis in the $\mathrm{OB}$.

\section{Analysis of neuroblasts in the granule cell layer}

To further rule out that mutant alpha-synuclein affects the maturation of progenitor cells in the $\mathrm{OB}$, we stereologically counted neuroblasts in the granule cell layer. We did not see a significant difference in the number of DCX-expressing neuroblasts in the granule cell layer. This provides evidence that the decreased olfactory neurogenesis in the alpha-synuclein transgenic group was not induced by a loss of bulbar neuroblasts but rather by a later event in the development of the neuron.

\section{Programmed cell death in the granule cell and glomerular layer of the $O B$}

Finally, we asessed programmed cell death by counting TUNELpositive cells in the granule cell and glomerular layers of all experimental groups (Table 1D). We found a significant increase in TUNEL-positive profiles in the A30P group compared to the control group in the granule cell layer $(P<0.01$; Fig. $5 \mathrm{~F})$, while the number of apoptotic profiles was similar to that of controls. In the glomerular layer we found a significant increase in apoptotic cells in the A30P group compared to the control group $(P<0.05)$. The number of apoptotic profiles was also reduced in this region in the A30P + dox group compared to the A30P group $(P<0.05)$.

\section{Discussion}

Conditional mouse models offer not only the opportunity to analyze transgene-induced pathology but also a unique chance to study the reversed effect at different time points. Our results show that in A30P alpha-synuclein mice transgene expression had a negative impact on the survival of newly generated interneurons in the $\mathrm{OB}$ regions at a late stage of neuronal development. Moreover, an increase in TUNEL-positive cells was observed, implying increased cell death in the OB of A30P mice. Suppression of A30P expression
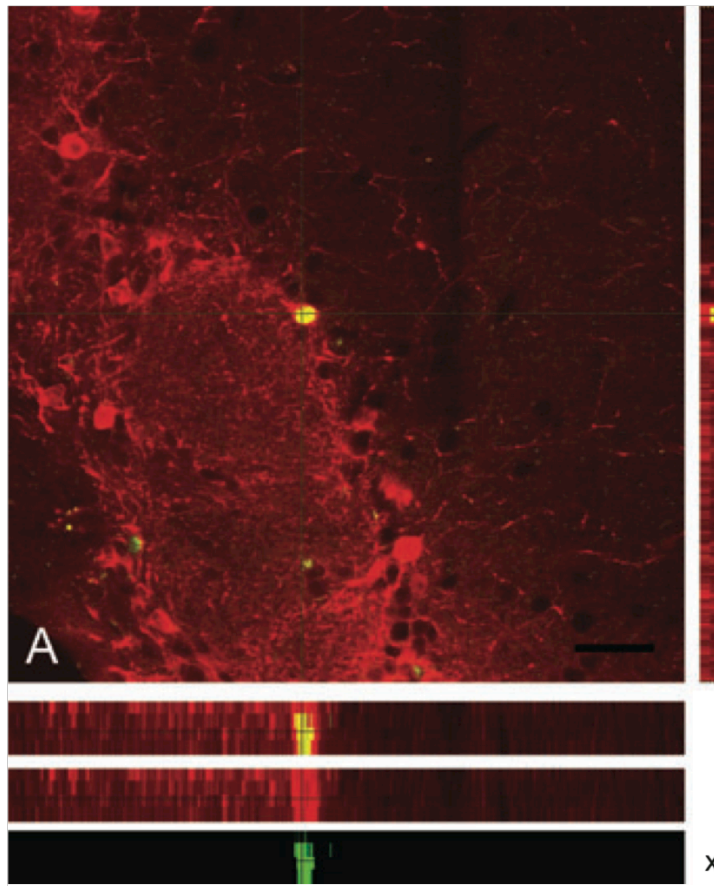

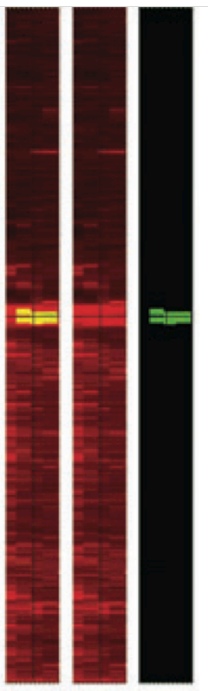

yz

E
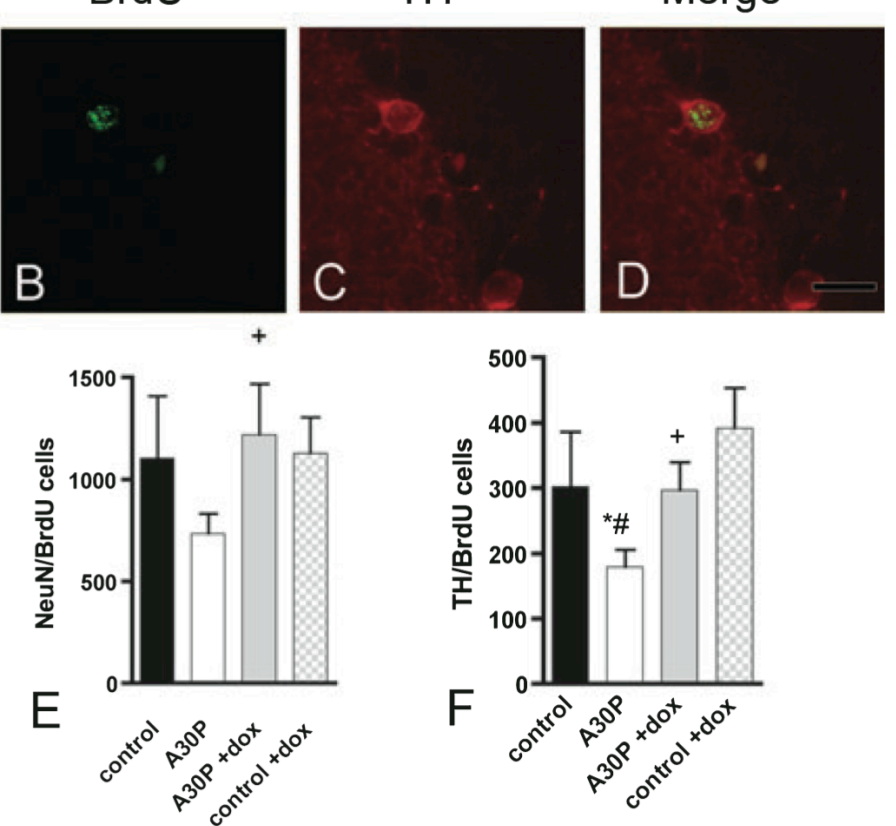

FIG. 7. Neurogenesis in the glomerular cell layer. Confocal analysis of (A, B and D, green) BrdU with (A, C and D, red) TH showed a reduced dopaminergic neurogenesis in the A30P group (for merged image, see D) that was $(\mathrm{F})$ reversible by blocking transgene expression in the A30P + dox group. (E) The number of newly generated neurons (total number of BrdU/NeuN coexpressing cells) was not decreased in A30P mice. Colabeling was analyzed sequentially at each wavelength and in the $z$-axis using 30 confocal planes. (E and F) Error bars are SD; ${ }^{*} P<0.001$ compared to control; ${ }^{\#} P<0.001$ compared to control + dox; ${ }^{+} P<0.001$ compared to A30P. Scale bars, $25 \mu \mathrm{m}(\mathrm{A}), 10 \mu \mathrm{m}$ (B-D). 
using the tet-off system resulted in restoration of neurogenic levels to levels observed in controls. This direct temporal correlation between transgene suppression and modulation of neurogenesis suggests an immediate association of alpha-synuclein on endogenous neural progenitors at the site of integration.

The $\mathrm{OB}$ is of particular interest because Lewy bodies and Lewy neurite formation occur at early stages of PD in humans (Braak et al., 2003), and olfactory dysfunction may be a valid surrogate biomarker for motor dysfunction at later stages of PD (Berendse et al., 2001; Siderowf et al., 2005). Studying endogenous stem cells and the interplay of their neuronal progenitors with alpha-synuclein in animal models of PD is important in understanding PD-related disease mechanisms.

\section{Alpha-synuclein induced a reduction in neurogenesis in the $O B$}

The CaMK promoter has previously been used to drive expression of CaMK-2Asp and the reporter gene lacZ in studies of memory formation (Mayford et al., 1996; Mansuy et al., 1998). We used the CaMK promoter because of the high expression in the $\mathrm{OB}$ and olfactory tubercle. The alpha-synuclein expression pattern of A30P mouse brains used in our study resembled the previously described CaMK expression pattern in the substantia nigra, the striatum and the OB (Ouimet et al., 1984; Erondu \& Kennedy, 1985). No alphasynuclein expression was present in any hippocampal region or in the cortex in our model. Variations such as differences in copy numbers or integration site of the transgene constructs, which have been described for both permanent (Maskri et al., 2004) and conditional (Mayford et al., 1996; Nuber et al., 2008) models, could account for these differences. CaMK has been described as a developmentally late neuronal promoter (Faison et al., 2002) and, thus, no alpha-synuclein expression was present in newly generated cells in the SVZ or the RMS of A30P mice. Attributing overexpression of A30P mutant alpha-synuclein to neurobiological changes in stem and progenitor cells in a cell-autonomous manner, the lack of alpha-synuclein expression in the SVZ might explain unchanged proliferation rates of stem and progenitor cells in this study.

In this study, we found a $30 \%$ decrease in granule cell and a $40 \%$ decrease in glomerular dopaminergic neurogenesis in the $\mathrm{OB}$ of $\mathrm{A} 30 \mathrm{P}$ mice. In previous studies wild-type alpha-synuclein reduced neurogenesis in the granule cell layer to $50 \%$ and in the glomerular layer to $59 \%$ in 4-month-old animals under a PDGF promoter (Winner et al., 2004). Aged A53T alpha-synuclein mutant mice with affected proliferation show neurogenesis decreased between 50\% for the granule cell layer and $64 \%$ for dopaminergic neurogenesis of the glomerular layer (Winner et al., 2007). We show that A30P mice expressed alpha-synuclein in neuronal progenitors no earlier than when they reached the OB granule cell layer, most probably due to the late induction of $\mathrm{CaMK}$ in newly generated cells. In addition, neuroblast numbers, as determined by stereological analysis for DCX, were unchanged in the granule cell layer. Considering the late induction of A30P expression in neuronal progenitors, the effects of $\mathrm{A} 30 \mathrm{P}$ on neurogenesis can be attributed to alpha-synuclein-induced effects occurring at the site of integration in the OB granule cell and glomerular layers. It is important to note that the decreased neurogenesis parallels the level of transgene expression; consecutively, the dopaminergic neurogenesis within the glomerular layer was more affected than in the granule cell layer.

We speculate that the presence of mutant alpha-synuclein impairs the integration process by a progenitor cell-intrinsic effect of alphasynuclein at the integration site of new neurons. This may be related to a late CaMK promoter-dependant expression of alpha-synuclein in neuroblasts. Alternatively, a cell-extrinsic effect, leading to impaired synaptic integration due to alpha-synuclein in cells at the site of integration of the neuroblasts, is also possible. Our study shows that newly generated granule neurons (to a large degree adopting a GABAergic neurotransmitter phenotype) were affected as well. In the glomerular layer a decrease in dopaminergic neurogenesis was observed. A potential explanation for cell death in dopaminergic neurons involves increased cellular toxicity in the presence of dopamine (Conway et al., 2001), leading to a larger decrease in dopaminergic neurons in the glomerular layer.

\section{Susceptibilty of endogenous neuronal progenitors to alpha-synuclein}

While neurodegeneration is a chronic and slowly proceeding process, our own in vivo data and cell culture data (Xu et al., 2002; Schneider et al., 2007; Winner et al., 2007) suggest that both wild-type and mutated (A53T, A30P) alpha-synuclein directly affect survival of neuronal progenitors in the adult brain. Developing neurons show vulnerable time points for impairment by alpha-synuclein during the proliferation phase and the differentiation phase, and during neuronal integration into the network (Schneider et al., 2007; Winner et al., 2007; Nuber et al., 2008). Besides the degeneration of the dopaminergic nigrostriatal system, understanding pathology in regions of early dysfunction in the course of the disease will foster our understanding of PD. Exploring alpha-synuclein-mediated effects in brain regions affected early in PD and targeting early cellular dysfunction will provide insights into initial steps in the pathogenesis of the disease.

\section{Alpha-synuclein expression in A30P mice}

The rapid transition from alpha-synuclein monomers into spherical protofibrils in cell-free models could explain the progressive character of the A30P point mutation (Conway et al., 2000), and cell culture models also indicate severe toxicity of A30P (Xu et al., 2002; Schneider et al., 2007). Transgenic mouse models that express A30P alpha-synuclein under the control of the Thy-1 promoter show intracellular accumulation of phosporylated A30P correlating with motor impairment and cognitive decline as well as an olfactory deficit (Freichel et al., 2007; Fleming et al., 2008). In these models, as well as in cell culture systems (Schneider et al., 2007), A30P is dispersed heterogenously in neurites and perikarya of the affected neurons. This pathological perikaryal and neuritic alpha-synuclein staining pattern was also present in our conditional A30P mice. Further indications for alpha-synuclein-induced degeneration was shown by ubiquitylation and silver staining. As both pathological features were reduced in dox-treated $\mathrm{A} 30 \mathrm{P}$ mice, it is possible that these alterations are reversible in our conditional A30P mice. Ubiquitinilation together with alpha-synuclein aggregation is a common finding in human PD tissue (Spillantini et al., 1997). In the present study, dox treatment of the A30P mice was started at the age of 2 months. Blocking transgene expression for 2 months resulted in the absence of alpha-synuclein immunoreactivity in all brain regions even in the OB glomerular cell layer, which presents with intensive alpha-synuclein staining in the untreated A30P animals.

\section{Direct modulation of neurogenesis via regulated $A 30 P$ expression}

Using an inducible system to modulate A30P alpha-synuclein expression allowed for the first time the observation of a direct correlation 
between the presence of alpha-synuclein and olfactory neurogenesis. Suppression of the transgene reversed the A30P-induced decrease in adult neurogenesis in the $\mathrm{OB}$. These findings make this animal model an ideal tool for further study of the effects of alpha-synuclein expression on neuronal progenitors. Previously, the toxic effects of alpha-synuclein on progenitors in cell culture experiments ( $\mathrm{Xu}$ et al., 2002; Schneider et al., 2007) lacked reproducibility in vivo as the mutant transgene was expressed constitutively. The results presented here show that the pathological effects of alpha-synuclein on neuronal progenitors are induced directly by the presence of alpha-synuclein. Further studies are needed to exactly delineate the temporal interplay of alpha-synuclein and adult neurogenesis and to determine whether A30P expression forms stable deposits at later time points.

In conclusion, this study reports for the first time the generation of a new conditional mouse model expressing A30P alpha-synuclein in several brain regions and its negative impact on adult neurogenesis in the SVZ/OB system. By turning off the transgene at an adult stage, A30P alpha-synuclein expression was downregulated and, importantly, the A30P-induced decrease in olfactory neurogenesis was reversed. This model is an ideal tool for evaluating novel therapeutical strategies as both neuronal cell loss and impaired neurogenesis contribute to disease pathology.

\section{Acknowledgements}

The authors would like to thank Leah Boyer for editing of the manuscript, Sonja Ploetz for continuous support and Francisco Rivera, Ludwig Aigner, Eliezer Masliah and Fred H. Gage for helpful comments. Support came from the Bavarian State Ministry of Sciences, Research and the Arts, ForNeuroCell (B.W., J.W.; Regensburg, Germany), the GSK fellowship for PD (B.W.), the Elite Network Bavaria (F.M., J.W.) and the German Research Foundation (Ri $682 / 6-1 / 2 / 3$ to O.R.). F.M. is supported by the Josef-Stanglmeier Foundation. M.K. was supported by the Albert-Raps-Foundation. B.W. is a Lynen-fellow of the Alexander von Humboldt Foundation.

\section{Abbreviations}

A30P, mutant human A30P alpha-synuclein; BrdU, bromodeoxyuridine; CaMK, calcium/calmodulin-dependent protein kinase II alpha; DCX, doublecortin; dkS, normal donkey serum; dox, doxycycline; NeuN, neuronal nuclei; $\mathrm{OB}$, olfactory bulb; PCNA, proliferating cellular nuclear antigen; $\mathrm{PD}$, Parkinson's disease; RMS, rostral migratory stream; SVZ, subventricular zone; tet-off, tetracycline-suppressive; TH, tyrosine hydroxylase; TUNEL, terminal deoxynucleotidyl transferase dUTP nick-end labeling

\section{References}

Berendse, H.W., Booij, J., Francot, C.M., Bergmans, P.L., Hijman, R., Stoof, J.C. \& Wolters, E.C. (2001) Subclinical dopaminergic dysfunction in asymptomatic Parkinson's disease patients' relatives with a decreased sense of smell. Ann. Neurol., 50, 34-41.

Biebl, M., Winner, B. \& Winkler, J. (2005) Caspase inhibition decreases cell death in regions of adult neurogenesis. Neuroreport, 16, 1147-1150.

Braak, H., Sandmann-Keil, D., Gai, W. \& Braak, E. (1999) Extensive axonal Lewy neurites in Parkinson's disease: a novel pathological feature revealed by alpha-synuclein immunocytochemistry. Neurosci. Lett., 265, 67-69.

Braak, H., Del Tredici, K., Rub, U., de Vos, R.A., Jansen Steur, E.N. \& Braak, E. (2003) Staging of brain pathology related to sporadic Parkinson's disease. Neurobiol. Aging, 24, 197-211.

Carleton, A., Petreanu, L.T., Lansford, R., Alvarez-Buylla, A. \& Lledo, P.M (2003) Becoming a new neuron in the adult olfactory bulb. Nat. Neurosci., 6 , $507-518$.

Conway, K.A., Harper, J.D. \& Lansbury, P.T. (1998) Accelerated in vitro fibril formation by a mutant alpha-synuclein linked to early-onset Parkinson disease. Nat. Med., 4, 1318-1320.

Conway, K.A., Lee, S.J., Rochet, J.C., Ding, T.T., Williamson, R.E. \& Lansbury, P.T. Jr (2000) Acceleration of oligomerization, not fibrillization, is a shared property of both alpha-synuclein mutations linked to early-onset Parkinson's disease: implications for pathogenesis and therapy. Proc. Natl Acad. Sci. USA, 97, 571-576.

Conway, K.A., Rochet, J.C., Bieganski, R.M. \& Lansbury, P.T. Jr (2001) Kinetic stabilization of the alpha-synuclein protofibril by a dopamine-alphasynuclein adduct. Science, 294, 1346-1349.

Curtis, M.A., Kam, M., Nannmark, U., Anderson, M.F., Axell, M.Z., Wikkelso, C., Holtas, S., van Roon-Mom, W.M., Bjork-Eriksson, T., Nordborg, C., Frisen, J., Dragunow, M., Faull, R.L. \& Eriksson, P.S. (2007) Human neuroblasts migrate to the olfactory bulb via a lateral ventricular extension. Science, 315, 1243-1249.

Doetsch, F., Caille, I., Lim, D.A., Garcia-Verdugo, J.M. \& Alvarez-Buylla, A. (1999) Subventricular zone astrocytes are neural stem cells in the adult mammalian brain. Cell, 97, 703-716

Erondu, N.E. \& Kennedy, M.B. (1985) Regional distribution of type II $\mathrm{Ca}^{2+} /$ calmodulin-dependent protein kinase in rat brain. J. Neurosci., 5, 3270-3277.

Faison, M.O., Perozzi, E.F., Caran, N., Stewart, J.K. \& Tombes, R.M. (2002) Axonal localization of delta $\mathrm{Ca}^{2+} /$ calmodulin-dependent protein kinase II in developing P19 neurons. Int. J. Dev. Neurosci., 20, 585-592.

Fleming, S.M., Tetreault, N.A., Mulligan, C.K., Hutson, C.B., Masliah, E. \& Chesselet, M.F. (2008) Olfactory deficits in mice overexpressing human wildtype alpha-synuclein. Eur. J. Neurosci., 28, 247-256.

Freichel, C., Neumann, M., Ballard, T., Muller, V., Woolley, M., Ozmen, L., Borroni, E., Kretzschmar, H.A., Haass, C., Spooren, W. \& Kahle, P.J. (2007) Age-dependent cognitive decline and amygdala pathology in alpha-synuclein transgenic mice. Neurobiol. Aging, 28, 1421-1435.

Gai, W.P., Blessing, W.W. \& Blumbergs, P.C. (1995) Ubiquitin-positive degenerating neurites in the brainstem in Parkinson's disease. Brain, 118 $(\mathrm{Pt}$ 6), 1447-1459.

Gallyas, F. (1971) Silver staining of Alzheimer's neurofibrillary changes by means of physical development. Acta Morphol Acad Sci Hung, 19, 1-8.

Gavrieli, Y., Sherman, Y. \& Ben-Sasson, S.A. (1992) Identification of programmed cell death in situ via specific labeling of nuclear DNA fragmentation. J. Cell Biol., 119, 493-501.

Giasson, B.I., Murray, I.V., Trojanowski, J.Q. \& Lee, V.M. (2001) A hydrophobic stretch of 12 amino acid residues in the middle of alphasynuclein is essential for filament assembly. J. Biol. Chem., 276, 23802386.

Gibb, W.R. \& Lees, A.J. (1988) The relevance of the Lewy body to the pathogenesis of idiopathic Parkinson's disease. J. Neurol. Neurosurg. Psychiatry, 51, 745-752.

Gossen, M. \& Bujard, H. (1992) Tight control of gene expression in mammalian cells by tetracycline-responsive promoters. Proc. Natl Acad. Sci. USA, 89, 5547-5551.

Gundersen, H.J., Bendtsen, T.F., Korbo, L., Marcussen, N., Moller, A., Nielsen, K., Nyengaard, J.R., Pakkenberg, B., Sorensen, F.B. \& Vesterby, A. (1988) Some new, simple and efficient stereological methods and their use in pathological research and diagnosis. Apmis, 96, 379-394

Kahle, P.J., Neumann, M., Ozmen, L., Muller, V., Jacobsen, H., Schindzielorz, A., Okochi, M., Leimer, U., van Der Putten, H., Probst, A., Kremmer, E., Kretzschmar, H.A. \& Haas, C. (2000) Subcellular localization of wild-type and Parkinson's disease-associated mutant alpha synuclein in human and transgenic mouse brain. J. Neurosci., 20, 6365-6373.

Kruger, R., Kuhn, W., Muller, T., Woitalla, D., Graeber, M., Kosel, S., Przuntek, H., Epplen, J.T., Schols, L. \& Riess, O. (1998) Ala30Pro mutation in the gene encoding alpha-synuclein in Parkinson's disease. Nat. Genet., 18, $106-108$.

Lois, C., Garcia-Verdugo, J.M. \& Alvarez-Buylla, A. (1996) Chain migration of neuronal precursors. Science, 271, 978-981.

Mansuy, I.M., Winder, D.G., Moallem, T.M., Osman, M., Mayford, M., Hawkins, R.D. \& Kandel, E.R. (1998) Inducible and reversible gene expression with the rtTA system for the study of memory. Neuron, 21, 257265.

Maskri, L., Zhu, X., Fritzen, S., Kuhn, K., Ullmer, C., Engels, P., Andriske, M., Stichel, C.C. \& Lubbert, H. (2004) Influence of different promoters on the expression pattern of mutated human alpha-synuclein in transgenic mice. Neurodegener. Dis., 1, 255-265.

Mayford, M., Bach, M.E., Huang, Y.Y., Wang, L., Hawkins, R.D. \& Kandel, E.R. (1996) Control of memory formation through regulated expression of a CaMKII transgene. Science, 274, 1678-1683.

Montgomery, E.B. Jr, Koller, W.C., LaMantia, T.J., Newman, M.C., SwansonHyland, E., Kaszniak, A.W. \& Lyons, K. (2000) Early detection of probable idiopathic Parkinson's disease: I. Development of a diagnostic test battery. Mov. Disord., 15, 467-473. 
Neumann, M., Kahle, P.J., Giasson, B.I., Ozmen, L., Borroni, E., Spooren, W., Muller, V., Odoy, S., Fuuiwara, H., Hasegawa, M., Iwatsubo, T., Trojanowski, J.Q., Kretzschmar, H.A. \& Haas, C. (2002) Misfolded proteinase K-resistant hyperphosphorylated alpha-synuclein in aged transgenic mice with locomotor deterioration and in human alpha-synucleinopathies. J. Clin. Invest., 110, 1429-1439.

Nuber, S., Petrasch-Parwez, E., Winner, B., Winkler, J., von Horsten, S., Schmidt, T., Boy, J., Kuhn, M., Nguyen, H.P., Teismann, P., Schulz, J.B., Neumann, M., Pichler, B.J., Reischl, G., Holzmann, C., Schmitt, I., Bornemann, A., Kuhn, W., Zimmermann, F., Servadio, A. \& Riess, O. (2008) Neurodegeneration and motor dysfunction in a conditional model of Parkinson's disease. J. Neurosci., 28, 2471-2484.

Ouimet, C.C., McGuinness, T.L. \& Greengard, P. (1984) Immunocytochemical localization of calcium/calmodulin-dependent protein kinase II in rat brain. Proc. Natl Acad. Sci. USA, 81, 5604-5608.

Paxinos, G. \& Franklin, K.B. (2001) The Mouse Brain in Stereotaxic Coordinates, 2nd edn. Academic Press, San Diego, CA.

Sanai, N., Tramontin, A.D., Quinones-Hinojosa, A., Barbaro, N.M., Gupta, N., Kunwar, S., Lawton, M.T., McDermott, M.W., Parsa, A.T., Manuel-Garcia Verdugo, J., Berger, M.S. \& Alvarez-Buylla, A. (2004) Unique astrocyte ribbon in adult human brain contains neural stem cells but lacks chain migration. Nature, 427, 740-744.

Schneider, B.L., Seehus, C.R., Capowski, E.E., Aebischer, P., Zhang, S.C. \& Svendsen, C.N. (2007) Over-expression of alpha-synuclein in human neural progenitors leads to specific changes in fate and differentiation. Hum. Mol. Genet., 16, 651-666.

Shults, C.W., Rockenstein, E., Crews, L., Adame, A., Mante, M., Larrea, G., Hashimoto, M., Song, D., Iwatsubo, T., Tsuboi, K. \& Masliah, E. (2005)
Neurological and neurodegenerative alterations in a transgenic mouse model expressing human alpha-synuclein under oligodendrocyte promoter: implications for multiple system atrophy. J. Neurosci., 25, 10689-10699.

Siderowf, A., Newberg, A., Chou, K.L., Lloyd, M., Colcher, A., Hurtig, H.I., Stern, M.B., Doty, R.L., Mozley, P.D., Wintering, N., Duda, J.E., Weintraub, D. \& Moberg, P.J. (2005) [99mTc]TRODAT-1 SPECT imaging correlates with odor identification in early Parkinson disease. Neurology, 64, 17161720 .

Spillantini, M.G., Schmidt, M.L., Lee, V.M., Trojanowski, J.Q., Jakes, R. \& Goedert, M. (1997) Alpha-synuclein in Lewy bodies. Nature, 388, 839840 .

Valente, E.M., Salvi, S., Ialongo, T., Marongiu, R., Elia, A.E., Caputo, V., Romito, L., Albanese, A., Dallapiccola, B. \& Bentivoglio, A.R. (2004) PINK1 mutations are associated with sporadic early-onset parkinsonism. Ann. Neurol., 56, 336-341.

Winner, B., Cooper-Kuhn, C.M., Aigner, R., Winkler, J. \& Kuhn, H.G. (2002) Long-term survival and cell death of newly generated neurons in the adult rat olfactory bulb. Eur. J. Neurosci., 16, 1681-1689.

Winner, B., Lie, D.C., Rockenstein, E., Aigner, R., Aigner, L., Masliah, E., Kuhn, H.G. \& Winkler, J. (2004) Human wild-type alpha-synuclein impairs neurogenesis. J. Neuropathol. Exp. Neurol., 63, 1155-1166.

Winner, B., Rockenstein, E., Lie, D.C., Aigner, R., Mante, M., Bogdahn, U., Couillard-Depres, S., Masliah, E. \& Winkler, J. (2007) Mutant alphasynuclein exacerbates age-related decrease of neurogenesis. Neurobiol. Aging, 29, 913-925.

Xu, J., Kao, S.Y., Lee, F.J., Song, W., Jin, L.W. \& Yankner, B.A. (2002) Dopamine-dependent neurotoxicity of alpha-synuclein: a mechanism for selective neurodegeneration in Parkinson disease. Nat. Med., 8, 600-606. 


\section{$9 \quad$ Anhang}

\subsection{Verzeichnis der verwendeten Abkürzungen}

\begin{tabular}{ll} 
BDNF & Brain derived neurotrophic factor \\
BrdU & 5'-Bromodeoxyuridin \\
CaMK & Kalzium/Calmodulin- abhängigen Protein Kinase II alpha \\
DCX & Doublecortin \\
GABA & Gamma-aminobutyric acid \\
IPS & Idiopathisches Parkinsonsyndrom \\
NeuN & Neuronal Nuclei Antigen \\
NSC & Neurale Stammzellen \\
OB & Bulbus Olfaktorius \\
PCNA & Proliferating cell nuclear antigen \\
PDGF & Platelet derived growth factor \\
PSA-NCAM & Poly-Sialated Neural Cell Adhesion Molecule \\
REM & Rapid eye movement \\
RMS & Rostraler migratorischer Strom \\
Sox2 & SRY (sex determining region Y)-box 2 \\
SVZ & Subventrikuläre Zone \\
TH & Tyrosinhydroxylase \\
TUNEL & Terminal doeoxynucleotidyl transferase (dUTP) nick-end labeling \\
ZNS & Zentralnervensystem \\
& \\
\hline
\end{tabular}




\subsection{Danksagung}

Mein besonderer Dank geht an PD Dr. Beate Winner, welche mir das Thema dieser Arbeit anvertraut hat. Sie hat mich in die Forschung eingeführt und war in allen Schritten dieser Arbeit eine ermutigende und unterstützende Betreuerin.

Prof. Dr. Jürgen Winkler möchte ich für das mir entgegengebrachte Vertrauen, die Unterstützung, den wissenschaftlichen Diskurs und die außergewöhnlich guten Arbeitsbedingungen in seiner Forschungsgruppe besonders danken.

Mein Dank gilt weiterhin Prof. Dr. U. Bogdahn, der die Durchführung dieser Arbeit an der Klinik und Poliklinik für Neurologie ermöglicht und unterstützt hat.

Zusätzlich gilt mein Dank dem ganzen Team des Neurogenese Labors für dessen tatkräftige Unterstützung insbesondere Robert Aigner, PD Dr. Jochen Klucken und Sonja Plötz. Darüber hinaus möchte ich Prof. Dr. Ludwig Aigner und PD Dr. Sébastien Couillard-Despres für ihre Hilfe, für ihre guten Ratschläge und für ihre Freundschaft danken.

Schließlich möchte ich meiner Familie und meinen Freunden (insbesondere Andi, David, Hias und Uli) für deren Unterstützung bei dieser Arbeit und im Privaten von ganzem Herzen danken. 


\subsection{Lebenslauf}

\section{Franz Marxreiter}

\section{Persönliche Angaben}

- Geburtsdatum: 10.07.1981

- Geburtsort: Regensburg

- Staatsangehörigkeit: deutsch

- Familienstand: ledig

\section{Schulische Laufbahn, Zivildienst}

- Donau-Gymnasium Kelheim, Abiturnote: 2,0

1992-200 1

- Ersatzdienst in der Krankenpflege des Kreiskrankenhauses Kelheim

\section{Universitärer Werdegang}

- Studium der Humanmedizin

(vorklinischer Abschnitt) an der Johann- Wolfgang von Goethe

Universität Frankfurt am Main

ärztliche Vorprüfung (Physikum), Ergebnis: 2,0

(klinischer Abschnitt) an der Universität Regensburg

2005-2009

Staatsexamen Humanmedizin, Ergebnis 2,0

Nov 2009

- Masterstudiengang „Experimental and Clinical

ab März 2006

Neurosciences“ im Elitenetzwerk Bayern an der Universität

Regensburg

Masterprüfung

Februar 2010

\section{Promotion und Masterarbeit}

\section{- Promotion:}

Changes in adult olfactory bulb neurogenesis in mice expressing the A30P mutant form of alpha-synuclein

(Betreuung: PD Dr. med. Beate Winner, Klinik und Poliklinik für Neurologie, Universität Regensburg)

- Masterarbeit:

Analysis of hippocampal neurogenesis in a regulatable mouse model of synucleinopathies (Betreuer: Prof. Dr. med. Jürgen Winkler, Molekulare Neurologie, Universitätsklinikum Erlangen) 


\section{Präsentationen und Veröffentlichungen}

\section{Veröffentlichungen}

- Marxreiter F, Nuber S, Kandasamy M, Klucken J, Aigner R,

2009

Burgmayer R, Couillard-Déspres S, Riess O, Winkler J, Winner

B. Changes in adult olfactory bulb neurogenesis in mice

expressing the A30P mutant form of alpha-synuclein. Eur J

Neurosci (2009) vol. 29(5) pp. 879-890, Impact Factor: 3,67

\section{Poster}

- Marxreiter F, Nuber S, Winkler J, Winner B, Rieß O. Reduktion der adulten Neurogenese im A30P Synucleinmodell. Aktuelle Neurologie 2006; P315.

- Marxreiter F, Nuber S, Kandasamy M, Klucken J, Aigner R, Burgmayer R, Couillard-Déspres S, Riess O, Winkler J, Winner B. A30P alpha-synuclein expression regulates adult olfactory bulb neurogenesis. Symposium des Bayerischen Forschungsverbundes Adulte Neurale Stammzellen

\section{Vorträge}

Marxreiter F, Changes in adult neurogenesis in mice expressing mutant alpha-synuclein Opening Reception. ECN Studiengang 2008.

Marxreiter F, Nuber S, Winkler J, Winner B, Rieß O

Die adulte Neurogenese im Bulbus olfactorius ist reduziert im transgenen Mausmodell mit Expression der mutierten A30P Isoform des alpha-Synuclein. wissenschaftliche Sitzung der AG Zellersatz und Regeneration, $\underline{6}$. Deutscher Parkinsonkongress, Deutsche Parkinson Gesellschaft

\section{Stipendien}

- Josef-Stanglmeier-Stiftung, 93326 Abensberg 